\title{
Study of 0.9PMN-0.1PT Dielectric Behaviour in Relation to the Nanostructure
}

\author{
E. Lattard $\left({ }^{1}\right)$, M. Lejeune $\left({ }^{1, *}\right)$, D. Imhoff $\left({ }^{2}\right)$, R. Guinebretière $\left({ }^{1}\right)$, \\ C. Elissalde $\left({ }^{3}\right)$ and P. Abelard $\left({ }^{1}\right)$ \\ $\left({ }^{1}\right)$ L M.C.T.S $\left({ }^{* *}\right)$, E.N S.C I., Limoges, France \\ $\left({ }^{2}\right)$ L.P.S $\left({ }^{* * *}\right)$, Université Paris-Sud, Orsay, France \\ $\left({ }^{3}\right)$ ICMCB, Université Bordeaux I, Pessac, France
}

(Received 8 July 1996, revised 19 December 1996, accepted 6 January 1997)

PACS.77.22 Gn - Dielectric loss and relaxation

PACS.77.84.Dy - Nobates, titanates, tantalates PZT ceramics, etc

PACS $3930 .+\mathrm{w}-$ Spectroscopic techniques

\begin{abstract}
PbMg}_{1 / 3} \mathrm{Nb}_{2 / 3} \mathrm{O}_{3}-x \mathrm{PbTiO}_{3}$ ceramics with $x=0,01$ were prepared with a $12 \mathrm{~mol} \% \mathrm{MgO}$ excess to obtain dense and perovskite phase materials after sintering. The delectric characterization has revealed that a local polarization appears at a $T_{\mathrm{d}}$ temperature largely above the temperature of the maximum of permittivity $\left(T_{\mathrm{m}}\right.$, respectively $-13^{\circ} \mathrm{C}$ and $+36{ }^{\circ} \mathrm{C}$ for $x=0$ and 01 ). This phenomena is consistent with the nucleation of polar clusters Moreover, a dielectric relaxation is observed for $09 \mathrm{PMN}-0.1 \mathrm{PT}-012 \mathrm{MgO}$, in a large frequency range (100 Hz $-1 \mathrm{GHz}$ ), which corresponds to a multi-Debye process with broadening of the relaxation time distribution as the temperature decreases. This suggests a nucleation and growth mechanism of polar clusters with decreasing temperature, which can result from the successive transitions of different compositions. This hypothesis was confirmed by the identification of large chemical heterogeneities on a nanometrıc scale by TEM using two spectroscopy techniques (EDXS and EELS), because of the association of low and high atomic number elements in the materials, different types of equipment and also the simulation of the patterns with standards. In fact, these quantitative analyses have revealed large fluctuations of the local composition around the nominal one lead and magnesium deficient areas enrıched in niobium coexist with nanodomains largely enriched in lead and slightly in magnesium, which the size depends on the titanium content. The origin of these heterogeneities in correlation with the reactions sequences durıng calcınation and sinterıng is discussed. in partıcular the addition of titanium contributes, by stabilizing the perovskite phase, to limit the diffusion of lead oxıde, which consequently increases the homogeneity of the ceramics. Due to such heterogeneities, the material remains mainly paraelectric up to very low temperatures This effect can be balanced by the application of a high electric field which induces the growth of the polar clusters by displacement of their interface with the paraelectric matrix and orientation of their polarization in the direction of the electric field which can lead to a macroscopic ferroelectric transition in specific conditions of temperature and electric field intensity. These different mechanisms relax in a frequency range which depends on the temperature and on the amplitude of the electric field.
\end{abstract}

(*) Author for correspondence (e-mail m.lejeune@ensci fr)

$\left({ }^{* *}\right)$ ESA 6015

$\left({ }^{* * *}\right)$ URA 0002

(C) Les Éditions de Physique 1997 
Résumé. - Des céramiques polycristallines du type $(1-x) \mathrm{PbMg}_{1 / 3} \mathrm{Nb}_{2 / 3} \mathrm{O}_{3}-x \mathrm{PbT}_{1} \mathrm{O}_{3}$ avec $x=0$ et $10 \%$ molaires ont été élaborées avec un excès de $\mathrm{MgO}(12 \%$ molaires $)$ permettant d'obtenir des matériaux denses de structure pérovskıte. Des mesures de permittivité diélectrique ont montré qu'une polarisation locale apparait dans ces matériaux à des températures $\left(T_{d}\right)$ largement supérieures à celles correspondant au maximum de permittivité ( $T_{\mathrm{m}}$ respectivement égale $\grave{\mathrm{a}}-13{ }^{\circ} \mathrm{C}$ et $+36^{\circ} \mathrm{C}$ pour $x=0$ et 0,10 ). Ceci est cohérent avec la formation de nanodomaines polaires au sein du matériau. Par ailleurs, une étude des caractérstiques diélectriques sur une large gamme de fréquence $\left(100 \mathrm{~Hz}-10^{9} \mathrm{~Hz}\right)$ fart apparaitre une relaxation de type multi-Debye, la distribution des temps de relaxation correspondants s'élargissant vers les basses fréquences lorsque la température dimınue. Ce phénomène peut être relié à un processus de nucléationcroissance des clusters polaires sur une large gamme de température, résultant des fluctuations de composition chimıque au sein du matériau identifiées à l'échelle nanométrique par deux techniques de spectroscopie (EDX et EELS) en microscopıe électronıque en transmission. En effet, ces analyses ont mis en évidence de larges fluctuations de composition autour de la composition nominale du matériau des zones appauvries en plomb et en magnésium et enrichies en niobium coexistent avec des nanodomaines fortement enrichis en plomb et légérement en magnésium dont la taille varie avec la teneur en tıtane. Nous avons cherché à corréler ces hétérogénéités aux mécanismes réactionnels intervenant au cours des traitements thermıques nécessaures à l'élaboration de ces céramiques, en particulier, il apparaît que le titane en stabilisant la phase pérovskite contribue à limiter la diffusion de l'oxyde de plomb et à augmenter ainsi le degré d'homogénéité du matériau. Du fart de ces fortes hétérogénértés chimiques, le matériau reste globalement paraélectrıque jusqu'à basse température mais le mécanisme de nucléatıon-croissance est accéléré par application d'un champ électrique de forte amplitude de telle sorte qu'en dessous d'une température $T_{\mathrm{t}}$ le matériau devient majoritairement ferroélectrique. Ces mécanismes correspondant à un déplacement de l'interface des domannes polaires avec la matrice paraélectrique et à une orientation des vecteurs polarisation dans la direction du champ électrique relaxent dans une gamme de fréquence fonction de la température et de l'amplitude du champ électrique.

\section{Introduction}

Based lead magnesium niobate materials have been mostly studied for the past thirty years for capacitive and electrostrictive applications because of their high dielectric constant associated with large field-induced strain. $\mathrm{PbMg}_{1 / 3} \mathrm{Nb}_{2 / 3} \mathrm{O}_{3}$ (PMN) is a perovskite-structure relaxor material: by opposition to a "normal" ferroelectric which shows a sharp ferroelectric-paraelectric phase transition at a well defined temperature (called the Curie temperature), PMN exhibits a Diffuse Phase Transition(DPT) appearing in the weak field permittivity versus temperature. In fact, the permittivity shows a broad maximum over a large range of temperature which is frequency dependent.

Different models have been successively proposed for the relaxor ferroelectrics such as PMN. The origin of the relaxor behaviour of PMN is generally explained through the random distribution of the two cations on the $\mathrm{B}$ sites of the $\mathrm{Pb}\left(\mathrm{B}^{\prime}, \mathrm{B}^{\prime \prime}\right) \mathrm{O}_{3}$ complex perovskite structure [1], which leads to the formation of polar nanodomains around $300^{\circ} \mathrm{C}$, that is to say largely above the temperature of the maximum permittivity $\left(-12^{\circ} \mathrm{C}\right)$ [2]. This local polarization corresponds to correlated atomic shifts of $\mathrm{B}$ cations along a [111] direction (rhombohedral axis) but as the polarization vectors of each polar domain are randomly oriented in the bulk, the global polarization is zero $[3,4]$. A relevant consequence of these models is that the relaxor material is an association of paraelectric phase and polar phase around the temperature of maximum permittivity. Moreover, it is clear that the amount of polar phase increases when 
the temperature decreases, but different evolutions of the material with temperature are proposed with an increase of the size of the polar domains or of their interaction with decreasing temperature $[5,6]$.

Otherwise, when an external field is applied, one can observe a transition between a quasi cubic phase with nanopolar domains in a ferroelectric phase with macropolar domains [7-9]. In particular, macroferroelectric domains have been detected in PMN from $230 \mathrm{~K}$ during cooling under a $4 \mathrm{kV} \mathrm{cm}^{-1}$ minimum field and in the $120 \mathrm{~K}$ to $230 \mathrm{~K}$ temperature range during heating. A similar transition was observed in a TEM study of $0.93 \mathrm{PMN}-0.07 \mathrm{PT}$ ceramics at $-170^{\circ} \mathrm{C}$ and results from the electron beam bending stress applied to the thin sample [10].

All these different results show that factors such as temperature, electric field and stress can induce in these 'materials the switching of a non polar isotropic phase in a polar anisotropic phase and consequently increase the size or the amount of the polar nanodomains, eventually up to macroferroelectric domains.

The purpose of this paper is to characterize the nanostructure of PMN-PT ceramics responsible for its specific electromechanical behaviour previously observed [11]. The initial nanostructure of the materials, before application of a high electric field is identified at different temperatures through weak-field permittivity measurements in a large frequency range. Secondly, the sensitivity of this nanostructure to the application of a high electric field is studied through DC electric field permittivity measurements. Lastly, the dependence of the field-induced nanostructure on the frequency of the electric field according to the range of temperature is obtained from the field-induced polarization measurements performed in the different corresponding conditions. Moreover, a large part of this paper is finally devoted to the determination of the nanoscale composition of the material by EDXS (Energy Dispersive X-ray Spectroscopy) and EELS (Electron Energy Loss Spectroscopy) by TEM, in order to characterize its chemical heterogeneity and forward explain the evolutions of the nanostructure with the different selected parameters (temperature, amplitude and frequency of electric field).

\section{Synthesis and Microstructural Characterization}

$(1-x) \mathrm{PMN}-x \mathrm{PT}$ ceramics with $x=0$ and 0.10 were prepared from high-purity-grade powders of $\mathrm{PbO}, \mathrm{MgO}, \mathrm{Nb}_{2} \mathrm{O}_{5}, \mathrm{TiO}_{2}$ according to a procedure described in earlier work [12]. An $\mathrm{MgO}$ excess $(12 \mathrm{~mol} \%$ ) was added to the initial mix to promote the formation of the perovskite phase and its stability during the sintering step, and to limit the presence of pyrochlore phase [13]. Compared to the second stabilization route developed by other investigators [14] and named "Columbite" one, the direct addition of a high initial $\mathrm{MgO}$ excess allows to avoid the two steps of powder elaboration: (1) reaction of $\mathrm{MgO}$ with $\mathrm{Nb}_{2} \mathrm{O}_{5}$ to synthesize colombite phase followed by (2) thermal reaction with $\mathrm{PbO}$. The industrial process is by this way considerably simplified.

The deficiency of every sintered sample in lead oxide was deduced from the weight loss during sintering added to the evaporated $\mathrm{PbO}$ content during calcination. It corresponds respectively to 4.8 and $5 \mathrm{~mol} \%$ for 0 and $10 \mathrm{~mol} \% \mathrm{PT}$. X-ray diffraction patterns were collected on a Debye Scherrer like diffractometer equipped with an horizontal INEL CPS 120 detector. A bent quartz crystal monochromator focuses the beam on the detector and the slit system is adjusted to accept only $\mathrm{CuK} \alpha_{1}$ radiation from a sealed X-ray tube. This setting, previously defined for capillary samples, allows to characterize flat samples with a convenient accuracy for structural Rietveld refinements [15]. No pyrochlore phase was detected for PMN-0.12MgO and the one identified on the surface of $0.9 \mathrm{PMN}-0.1 \mathrm{PT}-0.12 \mathrm{MgO}$ sample was eliminated by polishing. 
The theoretical densities of ceramics were determined from the relative amounts of phases and densification factors were deduced from the geometrıcal densities. They were around $94 \%$.

$\mathrm{X}$-ray diffraction patterns of the crushed PMN-0.12MgO sintered samples also revealed that free $\mathrm{MgO}$ was associated to the perovskite phase. It corresponds to micronic inter or intragranular inclusions identified by EPMA (Electron Probe MicroAnalysis) thanks to WDXS (Wavelength dispersion $\mathrm{X}$ spectrum) analysis. The evaluation of the amount of free $\mathrm{MgO}$ was realized by the measurement of the intensities of the (200) $\mathrm{MgO}$ and (110)perovskite X-ray diffraction lines. The observed intensities in such materials containing heavy atoms like lead are greatly affected by the microabsorption effects. In order to avoid this problem, a calibration was achieved: seven samples containing $3,4,6,9,12,25$ or $50 \mathrm{~mol} \% \mathrm{MgO}$ were prepared with fired stonchiometric powders, then the intensity ratios were measured in each cases. By this way, $6 \mathrm{~mol} \%$ of free $\mathrm{MgO}$ was found in the samples. Taking into account the initial $\mathrm{MgO}$ excess (12 $\mathrm{mol} \%$ ), we can conclude that $6 \mathrm{~mol} \%$ of $\mathrm{MgO}$ have diffused in the perovskite structure during sintering. As the pyrochlore phase $\left(\mathrm{Pb}_{2} \mathrm{Mg}_{0}{ }_{33} \mathrm{Nb}_{1.66} \mathrm{O}_{65}\right)$ previously identified [16] in the stoichiometric samples is $\mathrm{Mg}$ deficient compared to PMN, the stabilization of the perovskite phase can be explained by the partial insertion of $\mathrm{MgO}$ in the structure.

\section{Characterization of the Sensitivity of the PMN-PT Ceramics Nanostructure in Relation to the Temperature and to the Application of an Electric Field (Variable Amplitude and Frequency)}

3.1. Study of the Evolution of the 0.9PMN-0.1PT Nanostructure with DecreasING TEMPERATURE. - As shown below, the modification of the 0.9PMN-0.1PT nanostructure by variation of the temperature is deduced from weak-field permittivity measurements performed as a function of the frequency at different temperatures. So, the samples were preliminarily polished to optical quality $(1 \mu \mathrm{m})$ and sputtered with Au-Pd (80-20) alloy on both sides to form electrodes. Wires were then bonded on the two faces with a silver epoxy.

At first, dielectric measurements, carried out at $1 \mathrm{~V} / \mathrm{rms}$ on a low frequency range $(100 \mathrm{~Hz}-$ $10 \mathrm{kHz}$ ) from $-30^{\circ} \mathrm{C}$ to $250^{\circ} \mathrm{C}$ reveal that the $1 \mathrm{kHz}$ permittivity is maxımum at $-13.5^{\circ} \mathrm{C}$ and $+36{ }^{\circ} \mathrm{C}$ for PMN and $0.9 \mathrm{PMN}-0.1 \mathrm{PT}$ respectively.

Moreover, by reporting the inverse of the permittivity as a function of temperature for 0.9PMN-0.1PT-0.12MgO (Fig. 1), one can note that the Curie-Weiss law is no longer respected from a $T_{\mathrm{d}}$ temperature which is largely above the temperature of maximum permittivity $\left(T_{\mathrm{m}}\right)$.

In fact, the $T_{\mathrm{d}}$ temperature corresponds to the apparition of a local polarization $P$, which can be evaluated according to Cross [5] from the following relation:

$$
\left[\frac{\mathrm{d} E}{\mathrm{~d} P}\right]_{\mathrm{S}}=\alpha\left(T-T_{0}\right)+\alpha^{2} P^{2} \frac{T}{c^{P}}
$$

Consequently, the material can be described under $T_{\mathrm{d}}$ as polar clusters distributed in a paraelectric matrix.

In a second stage, the dielectric measurements at $1 \mathrm{~V} / \mathrm{rms}$ were carried out on a larger frequency range, from $100 \mathrm{~Hz}$ to $1 \mathrm{GHz}$ for different temperatures below $T_{\mathrm{d}}$.

The real part of the permittivity, reported as a function of the frequency (Fig 2) shows dielectric relaxation which can be attributed to a simple Debye mechanism for temperatures above $60{ }^{\circ} \mathrm{C}$ (high frequency relaxation) and to the addition of a low frequency dispersion characterized by a superposition of different Debye mechanisms below $60^{\circ} \mathrm{C}[17,18]$. 


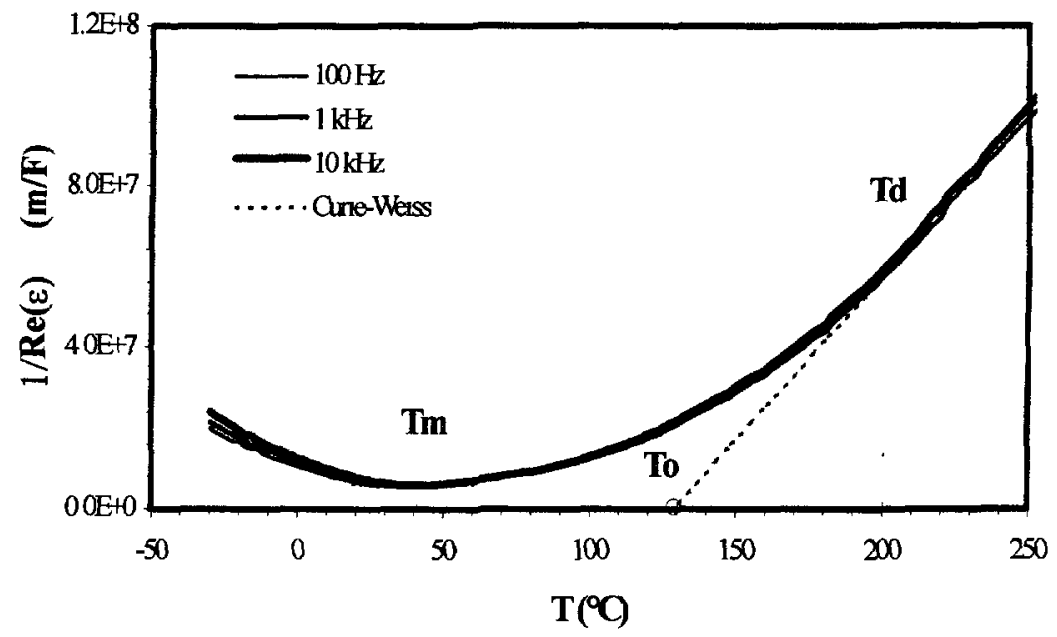

Fig. 1. - The inverse of the real part of the permittivity as a function of temperature for 0.9PMN0 1PT-0 12MgO.

Consequently, the imaginary part of the permittivity $\epsilon^{\prime \prime}$ as a function of the frequency can be decomposed at different temperatures in terms of a multi-Debye processes:

$$
\epsilon^{\prime \prime}(\omega)=\left(\epsilon_{\mathrm{S}}-\epsilon_{\infty}\right) \sum_{\imath} \frac{a_{\imath} \omega \tau_{2}}{1+\omega^{2} \tau_{\imath}^{2}}
$$

where $a_{\imath}$ is the weight coefficient which represents the contribution of each Debye term (Fig. 3). One can observe a relaxation time distribution which becomes larger with decreasing temperature, reflecting an increase of the low frequency contribution.

This distribution can be correlated to a nucleation and growth mechanism of the polar clusters below $T_{\mathrm{d}}$. In fact, as the stability of a polar domain increases with its size, the low relaxation times obtained at high temperature correspond to very small size polar clusters. When the temperature decreases, the broadening of the relaxation time distribution means that the size distribution of the clusters becomes larger.

3.2. Study of the Effect of a High Electric Field (Variable Amplitude and Frequency) on the Nanostructure of the Materials According to the Range of Temperature. - As previously shown by weak-field dielectric measurements in a large frequency range, $0.9 \mathrm{PMN}-0.1 \mathrm{P} \mathrm{T}-0.12 \mathrm{MgO}$ ceramics can be described under $T_{\mathrm{d}}$, as polar clusters distributed in a paraelectric matrix.

However, this material shows significant electromechanical responses under a high electric field (up to $2 \mathrm{kV} \mathrm{mm} \mathrm{mm}^{-1}$ ) [11]. Therefore, we have attempted to determine the sensitivity of the material to the application of a high electric field with variable amplitude and frequency in order to correlate further the electromechanical properties to the nanostructure.

3.2.1. Dielectric Permittivity Measurement under DC Electric Field. - At first, the effect of a DC electric field on the nanostructure of the materials is deduced from dielectric permittivity measurements, performed at $1 \mathrm{~V} / \mathrm{rms}$ in the $20 \mathrm{~Hz}-20 \mathrm{kHz}$ frequency range from $-20^{\circ} \mathrm{C}$ to $80^{\circ} \mathrm{C}$ under different $\mathrm{DC}$ biases. 

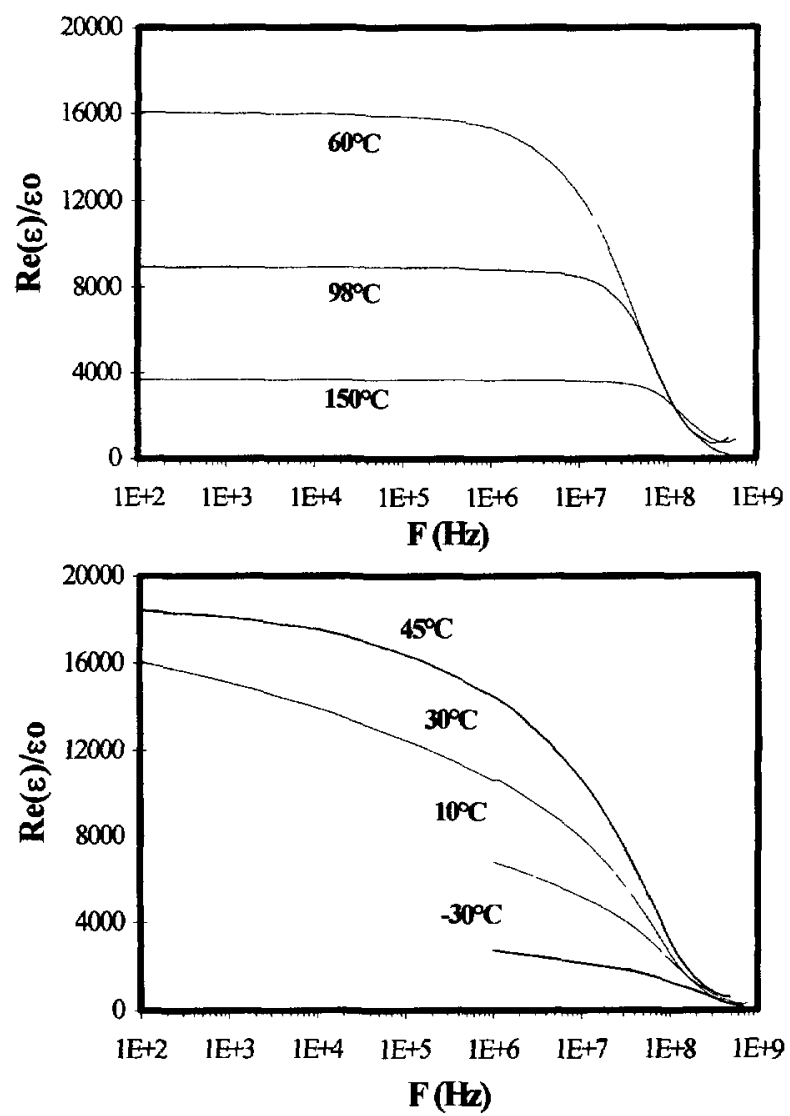

Fig. 2. - Real part of the permittivity as a function of frequency at different temperatures ( -30 , $150{ }^{\circ} \mathrm{C}$ ), for $0.9 \mathrm{PMN}-01 \mathrm{PT}-0.12 \mathrm{MgO}$.

As shown in Figure 4, the frequency dispersion of the imaginary part of the permittivity at $45^{\circ} \mathrm{C}$ is modified by application of a $0.5 \mathrm{kV} \mathrm{mm}{ }^{-1} \mathrm{DC}$ electric field, which corresponds to a variation of the size distribution of the polar domains. In fact, as observed in Figure 5 . the weight of the intermediate size domains increases correlatively to the application of a high electric field.

Moreover, for a constant $0.5 \mathrm{kV} \mathrm{mm}{ }^{-1} \mathrm{DC}$ bias, one can note (Fig. 6) that the weight of the small size polar domains $\left(a_{6}\right)$ continuously decreases with decreasing temperature. This growth mechanism is especially pronounced at a $T_{\mathrm{t}}$ temperature close to ambient. This room temperature phenomenon might be associated to the transition of the residual paraelectric matrix so that the material could be considered in a macroscopic ferroelectric state below this temperature. This hypothesis will have to be confirmed by TEM observations performed in similar conditions.

3.2.2. Field-Induced Polarization. - From field-induced polarization measurements, performed at different temperatures $\left(0^{\circ} \mathrm{C}-70^{\circ} \mathrm{C}\right)$ and frequencies $(1 \mathrm{mHz}-10 \mathrm{kHz})$, one searches to follow the evolution of the polar nanostructure with increasing electric field and the corresponding variations of this phenomenon with the (i) frequency of electric field and (ii) temperature. 

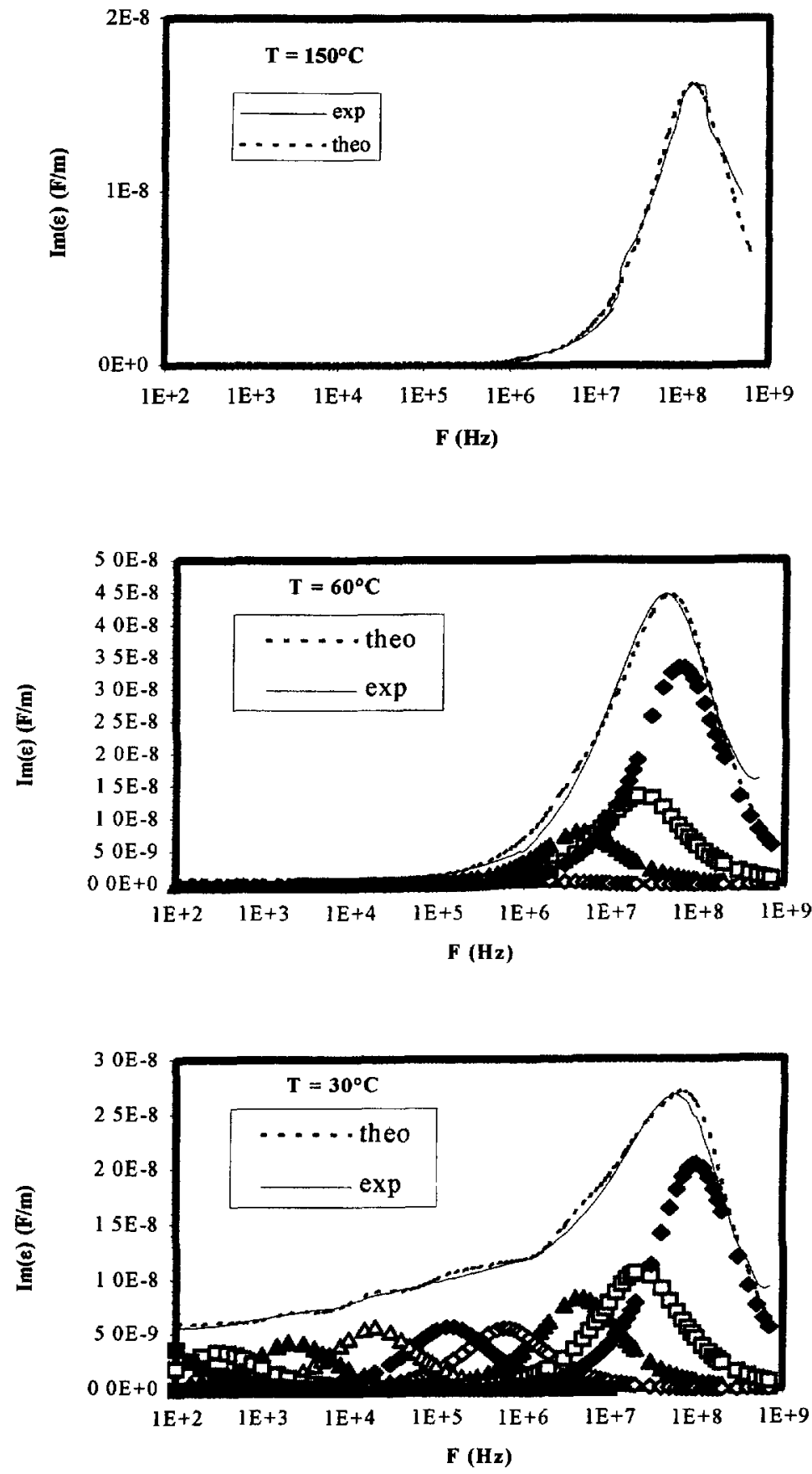

Fig 3. - Multi-Debye fitting of the imaginary part of the permittıvity as a function of the frequency for $0.9 \mathrm{PMN}-0.1 \mathrm{PT}-0.12 \mathrm{MgO}$ at different temperatures. 

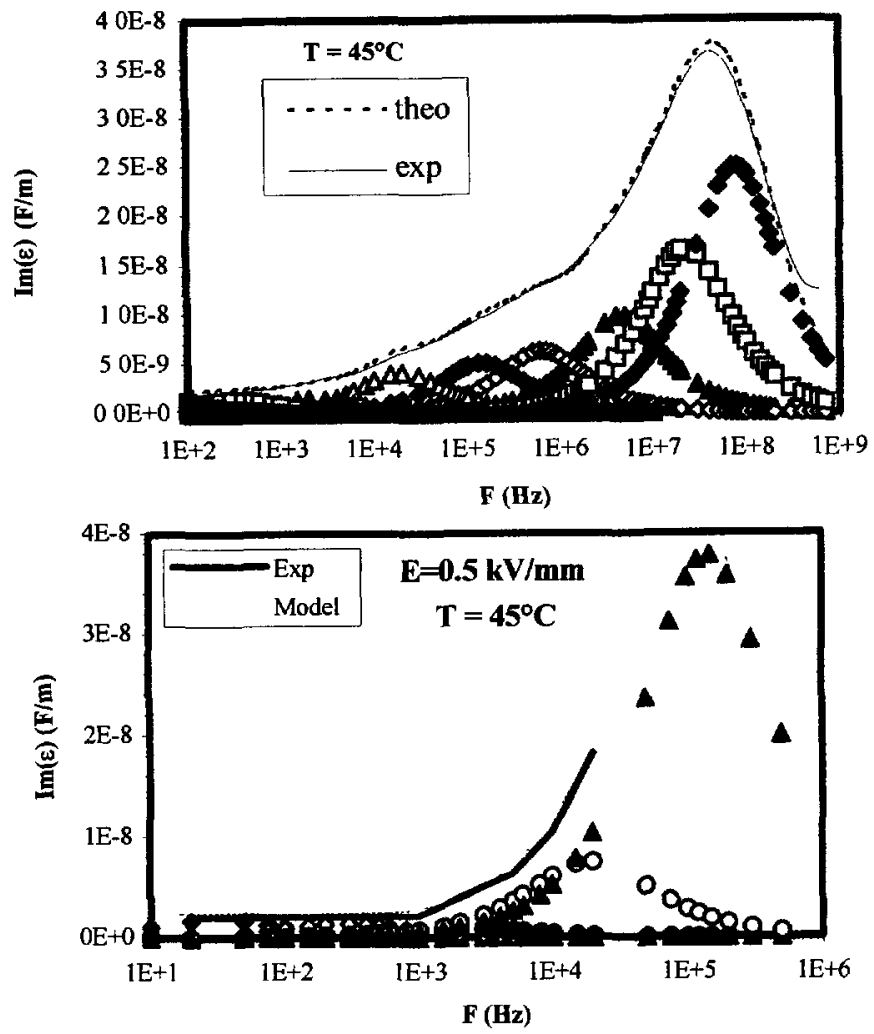

Fig. 4. - Mult1-Debye fitting of the imaginary part of the permittıvity as a function of the frequency for 0.9PMN-0.1PT-0.12MgO at $45{ }^{\circ} \mathrm{C}$ for 0 and $05 \mathrm{kV} \mathrm{mm}^{-1} \mathrm{DC}$ biases.

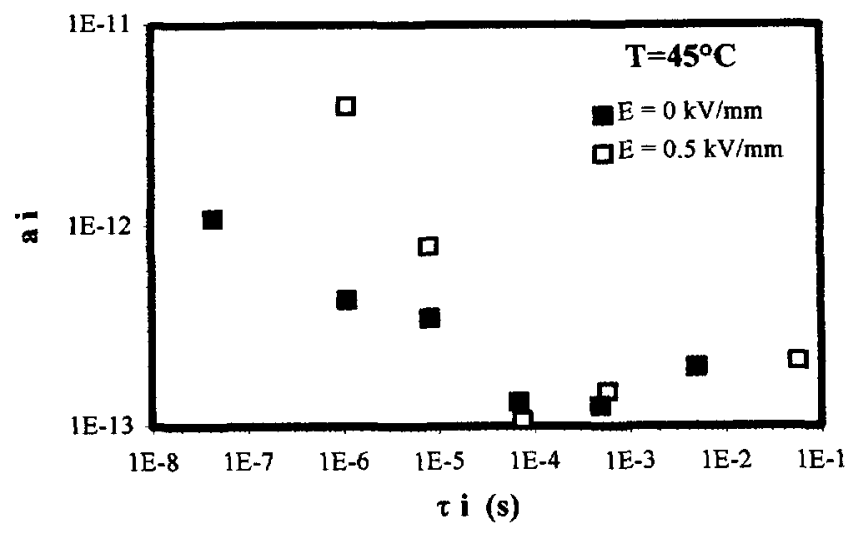

Fig 5. - Relaxation time distribution $a_{\imath}^{E}\left(\tau_{2}\right)$ for $09 \mathrm{PMN}-0.1 \mathrm{PT}-0.12 \mathrm{MgO}$ at $45{ }^{\circ} \mathrm{C}$ for 0 and $05 \mathrm{kV} \mathrm{mm}{ }^{-1} \mathrm{DC}$ biases. 


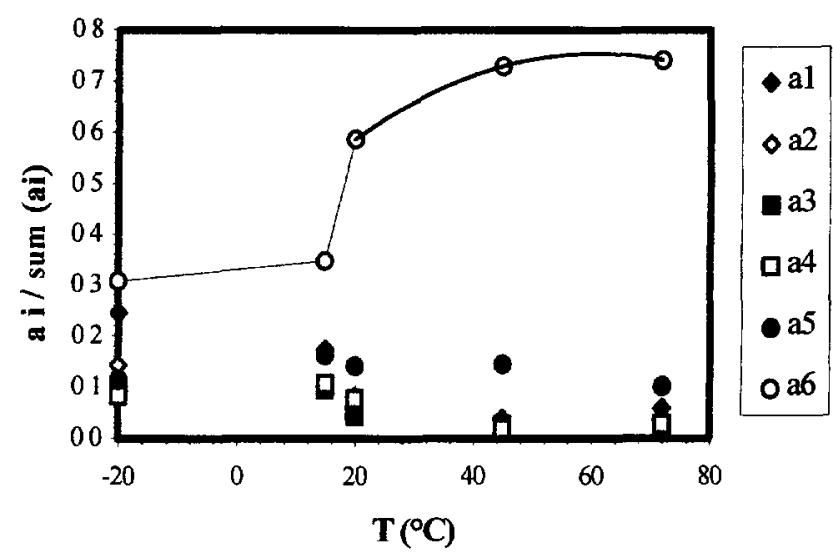

Fig. 6 - Relaxation time distribution $a_{\imath}^{\tau \imath}(T)$ (normalized to the sum of $a_{\imath}$ ) for $0.5 \mathrm{kV} \mathrm{mm} \mathrm{m}^{-1} \mathrm{DC}$ bias and 0.9PMN-0.1PT-0 12MgO composition.

The polarization was measured using a Sawyer-Tower circuit connected to a OX 7525 METRIX oscilloscope for data acquisition. The voltage was obtained with a TOE 7704 DIGAN frequency synthetiser $(1 \mathrm{mHz}$ to $12 \mathrm{MHz}$ ) connected to an AAP-4000-1 ADECE amplifier $(1600 \mathrm{~V}-1 \mathrm{~A})$.

Dependence of Low-Frequency Field-induced Polarization with Temperature. - Field-induced polarization $P(E)$ of PMN-0.12MgO and 0.9PMN-0.1PT-0 $12 \mathrm{MgO}$ at $20 \mathrm{mH} z$ and at different temperatures are reported in Figure 7.

At first, one can note that the field-induced polarization at $20 \mathrm{mHz}$ is largely improved by an addition of PT, which corresponds to an increase of the permittivity but also to a faster saturation mechanism. This evolution clearly appears in plotting the dynamic permittivity obtained from the first polarization curve $P(E)\left[\epsilon_{\mathrm{r}}=1 / \epsilon_{0} \mathrm{~d} P / \mathrm{d} E\right]$ (Fig. 8). In fact, taking into account the difference of maximum permittivity temperatures between $\mathrm{PMN}-0.12 \mathrm{MgO}$ and $0.9 \mathrm{PMN}-0.1 \mathrm{PT}-0.12 \mathrm{MgO}\left(\approx 50^{\circ} \mathrm{C}\right)$, we find similar $P(E)$ characteristics for the two materials.

Moreover, the $P(E)$ curves of $0.9 \mathrm{PMN}-0.1 \mathrm{PT}-0.12 \mathrm{MgO}$ can be analyzed through the evolution of the nanostructure of this material with an increasing electric field. Compared to a normal ferroelectric material, the $P(E)$ hysteresis can not be explained only by the displacement of the ferroelectric domain walls. In fact, according to the weak-field permittivity measurements, before the application of the electric field, the materials correspond to the distribution of nanopolar domains in a paraelectric matrix. Moreover, we have previously shown that the application of a high electric field promotes the transition of the paraelectric matrix. Therefore, the evolution of the polarization with an electric field (and correlatively of the permittivity) corresponds to the reorientation of the spontaneous. polarization vectors of the initial polar domains in parallel with $E$ and to the nucleation and growth of well oriented polar domains. Consequently, the surface of the $P(E)$ curves is associated to the dissipated energy in relation to a displacement of the interface between the nanopolar domains and the paraelectric matrix. This energy dissipation is due to some defects in the material.

So the strong evolution of the surface of $0.9 \mathrm{PMN}-0.1 \mathrm{PT}-0.12 \mathrm{MgO}$ ceramic hysteresis below $20^{\circ} \mathrm{C}$ is consistent with the hypothesis of a quasi-macroscopic ferroelectric transition of the material at this temperature. 

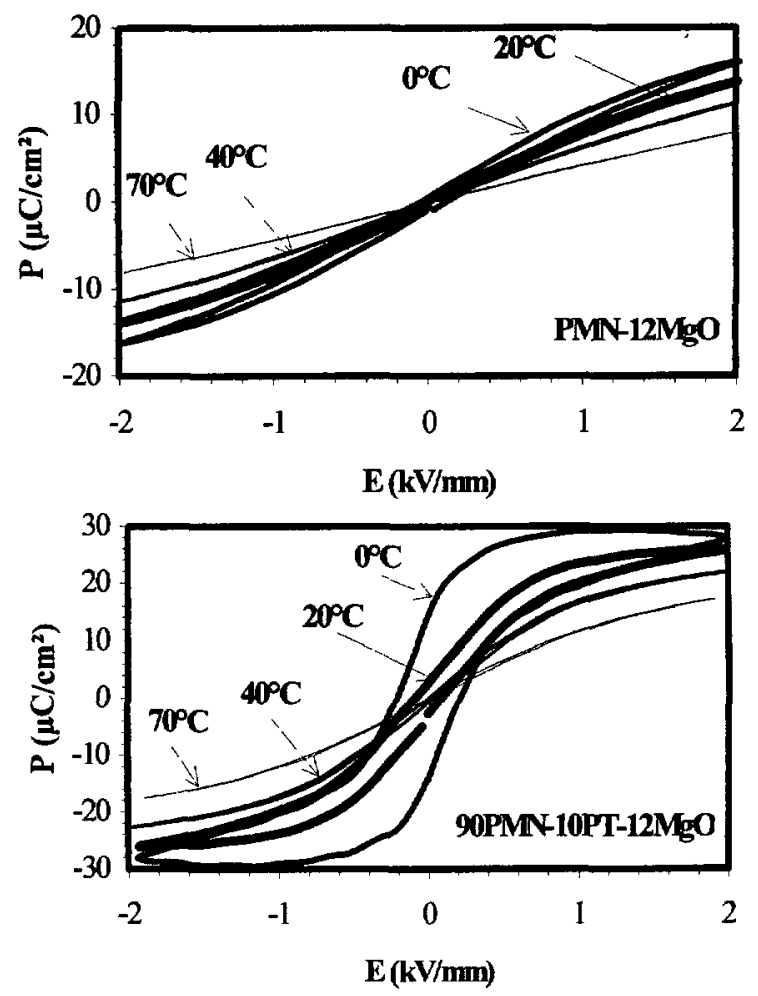

Fig. 7. $-P(E)$ hysteresis for $(1-x) \mathrm{PMN}-x \mathrm{PT}-12 \mathrm{MgO}$, with $x=0$ et $10 \mathrm{~mol} \%$, at different temperatures

Dependence of Field-induced Polarization on Frequency. - PMN-PT ceramics as actuators can be used under dynamic large-signal operating conditions. So, the sensitivity of the nanostructure to the variation of the electric field frequency must be analyzed to explain the corresponding electromechanical behaviour.

Figure 9 shows the polarization of $\mathrm{PMN}-0.12 \mathrm{MgO}$ and $0.9 \mathrm{PMN}-0.1 \mathrm{PT}-0.12 \mathrm{MgO}$ samples, respectively, versus electric field at two different frequencies: $20 \mathrm{mHz}$ and $3 \mathrm{kHz}$. The increase of the frequency from $20 \mathrm{mHz}$ to $3 \mathrm{kHz}$ has no sensitive effect on the maximum polarization induced by an electric field for PMN but leads to a notable decrease of the 0.9PMN-0.1PT one. Correlatively, the saturation mechanism at high electric fields progressively disappears for 0.9PMN-0.1PT and the surface of hysteresis increases.

This phenomenon is confirmed by plotting the maximum polarization $\left(E=1 \mathrm{kV} \mathrm{mm} \mathrm{m}^{-1}\right)$ as a function of the frequency, at different temperatures (Fig. 10a). Consequently, we can conclude that one contribution to the field-induced polarization mechanism for 0.9PMN-0.1PT$0.12 \mathrm{MgO}$ relaxes in a frequency range in relation to temperature. This relaxation mechanism is not inherent to the polarization of the paraelectric matrix and consequently not of ionic type, but it can result from the reorientation of the initial polar clusters or from the polar clusters-paraelectric matrix interface displacement by application of a DC electric field. The dependence of this relaxation mechanism with the amplitude of the electric field clearly appears in Figure 10b. 

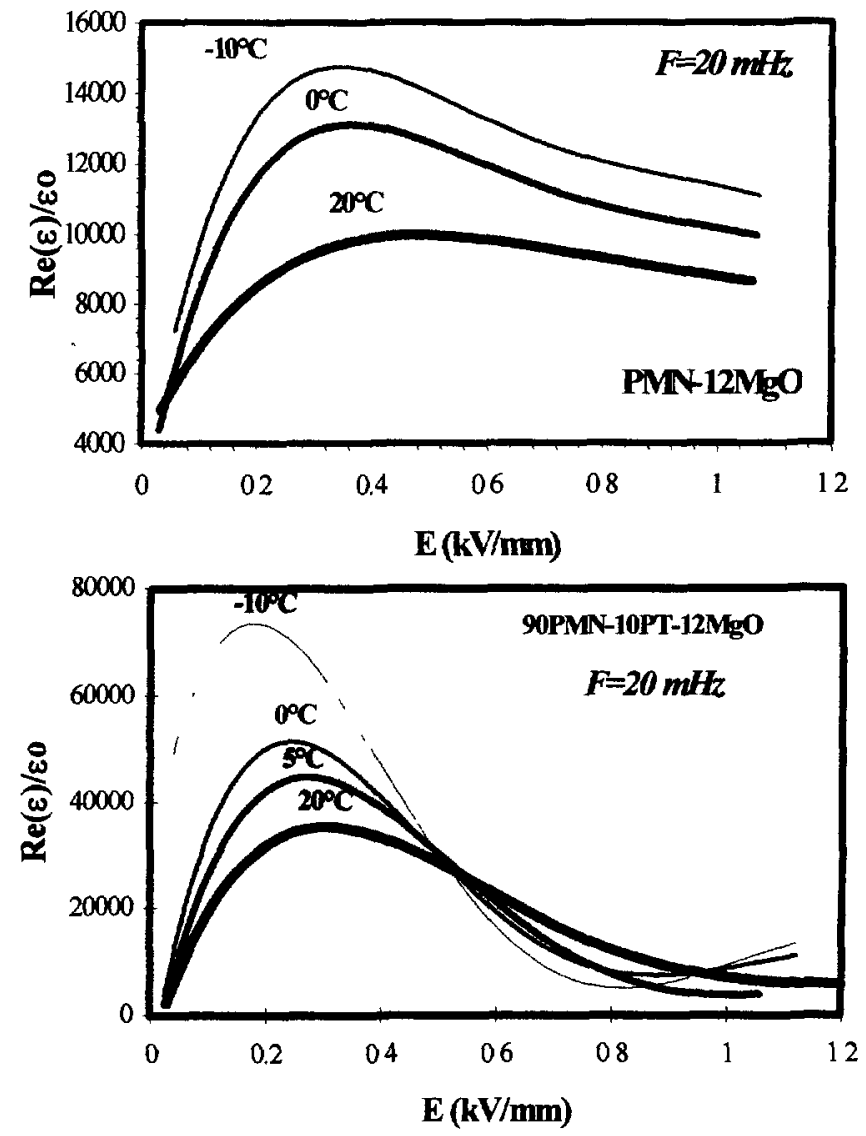

Fig. 8. - Permittivity as a function of the electric field for $(1-x) \mathrm{PMN}-x \mathrm{PT}-12 \mathrm{MgO}$ with $x=0$ et $10 \mathrm{~mol} \%$, at different temperatures.

In fact, the effect of temperature or intensity of the electric field on the amplitude and frequency of the relaxation mechanism can be explained respectively by the dependence of the nanostructure modification mechanism by application of a given electric field according to the range temperature and by the variable evolution of the nanostructure at a given temperature according to the intensity of the electric field.

\section{Identification of a Nanoscale Chemical Heterogeneity in the Sintered Samples}

The relaxor behaviour corresponding to a diffuse transition of the material in a large range of temperature can lead to a size distribution of the polar domains as a function of the temperature as previously proposed. This phenomenon has commonly been explained through chemical heterogeneities $[19,20]$. In fact, as each composition is characterized by a Curie temperature, consequently, the fluctuation of the composition through the material induces a diffuse transition. As this hypothesis has never been confirmed directly, nanoscale chemical analysis of PMN-PT materials were carried out through EDXS and EELS techniques. 

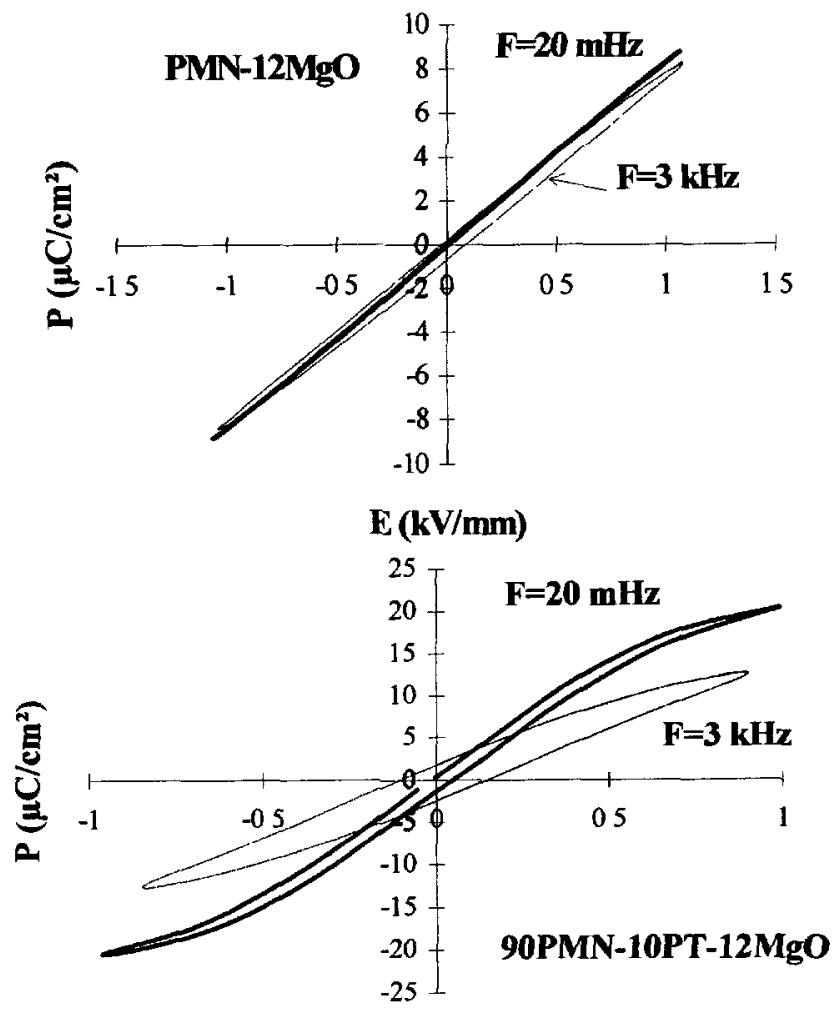

$\mathbf{E}(\mathrm{kV} / \mathrm{mm})$

Fig. 9. - Polarization at $20{ }^{\circ} \mathrm{C}$ versus electric field at $20 \mathrm{mHz}$ and $3 \mathrm{kHz}$ for PMN-0.12MgO and 0.9PMN-0.1PT-0.12MgO.

4.1. Preliminary Analysis. - In order to evaluate the cation ratio $\mathrm{Nb} / \mathrm{Mg}$ on the $\mathrm{B}$ perovskite site, the XRD patterns obtained for $\mathrm{PMN}-0.12 \mathrm{MgO}$ were analyzed by structural refinement. This study was performed following the Rietveld method with the "Fullprof" program [21]. Considering a fully disordered distribution of the $\mathrm{Mg}$ and $\mathrm{Nb}$ cations on the $\mathrm{B}$ site, the best fit was obtained for a $\mathrm{Nb} / \mathrm{Mg}$ ratio close to 3 . This corresponds to an enrichment in niobium of the perovskite phase, compared to a stoichiometric ratio equal to 2 , which must induce a local depletion of this cation.

These samples were observed by Transmission Electronic Microscopy. TEM samples were extracted from the center of the bulk material and were thinned first by mechanical polishing then by "standard" ion milling $\left(5 \mathrm{kV}, 0.5 \mathrm{~mA}\right.$, ion beam at $15^{\circ}$ over the sample surface).

The electron diffraction patterns obtained by selected area diffraction mode under the $\langle 110\rangle^{*}$ zone axis, exhibit characteristic $\frac{1}{2}\{111\}$ superlattice reflections. According to previous works [22] this superlattice could be associated with the presence of nanosized ordered domains with a B-site cation ratio of $\mathrm{Nb} / \mathrm{Mg}=1$.

Moreover, a careful analysis of the XRD patterns reveals an asymmetric broadening of the (h00) diffraction lines (Fig. 11). 

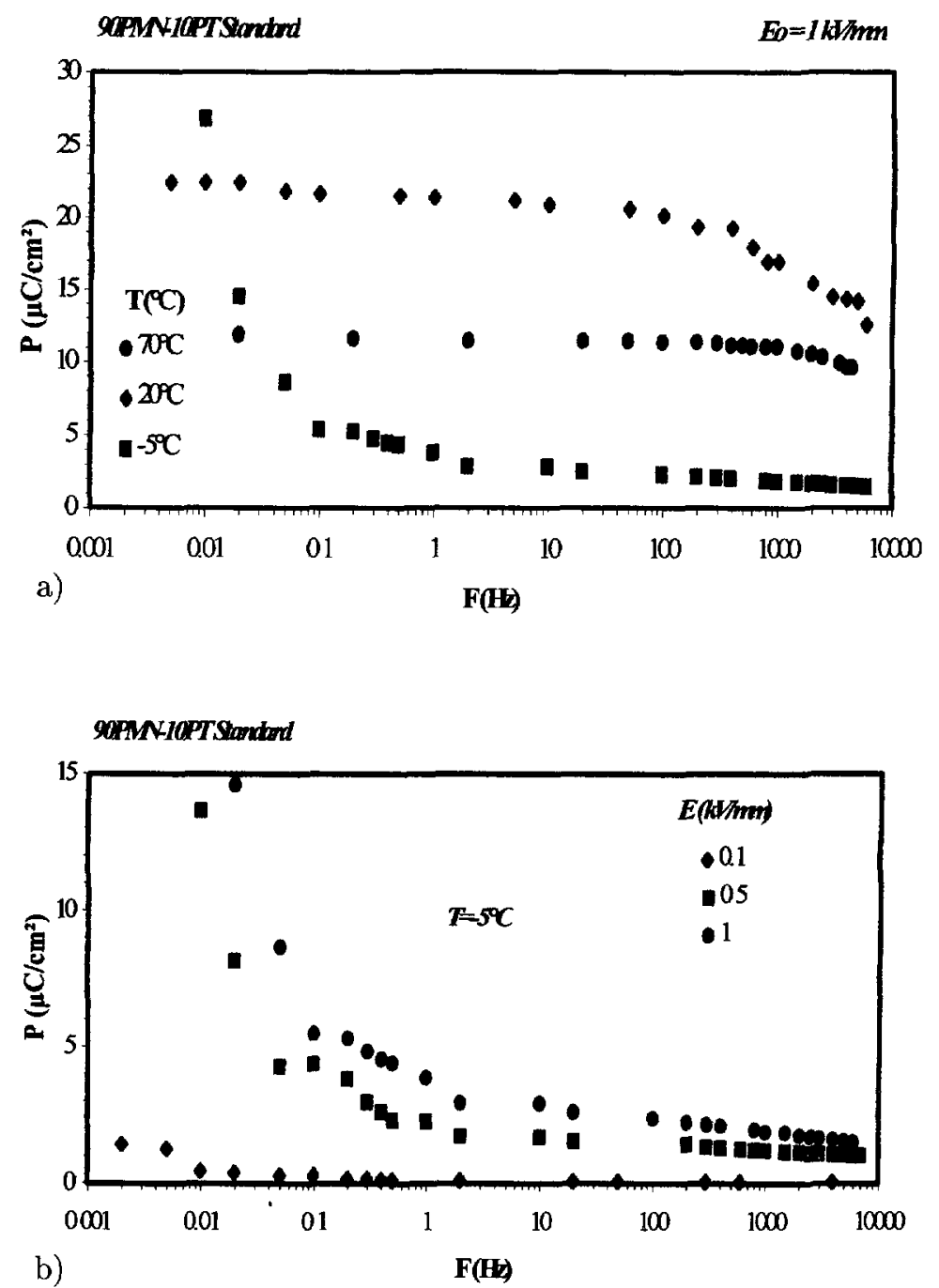

Fig 10. - Relaxation of the maximum polarization of 0.9PMN-0.1PT-0.12MgO (a) at $-5{ }^{\circ} \mathrm{C}, 20{ }^{\circ} \mathrm{C}$ and $70^{\circ} \mathrm{C}$ for $E=1 \mathrm{kV} \mathrm{mm}^{-1}$ and (b) at $-5^{\circ} \mathrm{C}$ for $E=0.1,0.5,1 \mathrm{kV} \mathrm{mm}^{-1}$.

This profile widening is in agreement with the previous observations made by Mathan et al. [3]. This phenomenon was then correlated to nanoscale chemical composition fluctuations associated with coherent atoms shifts in the corresponding crystallographic cells. The Miller indices of the broadened lines are related to the crystalline symmetry of the segregated regions. The identification of this symmetry will not be discussed here but it is noticeable that this line broadening is always in the small angles side. The modification of the perovkite cell parameter induced by a decrease of niobium content on the B-site corresponds to a decrease of the diffraction angles; therefore, the observed diffraction lines deformation is in agreement with the presence of nanometric regions with a low niobium content.

In order to confirm these results, HRTEM (High Resolution Transmission Electron Mlcroscopy) observations were carried out. A high resolution image obtained under the $\langle 001\rangle^{*}$ 


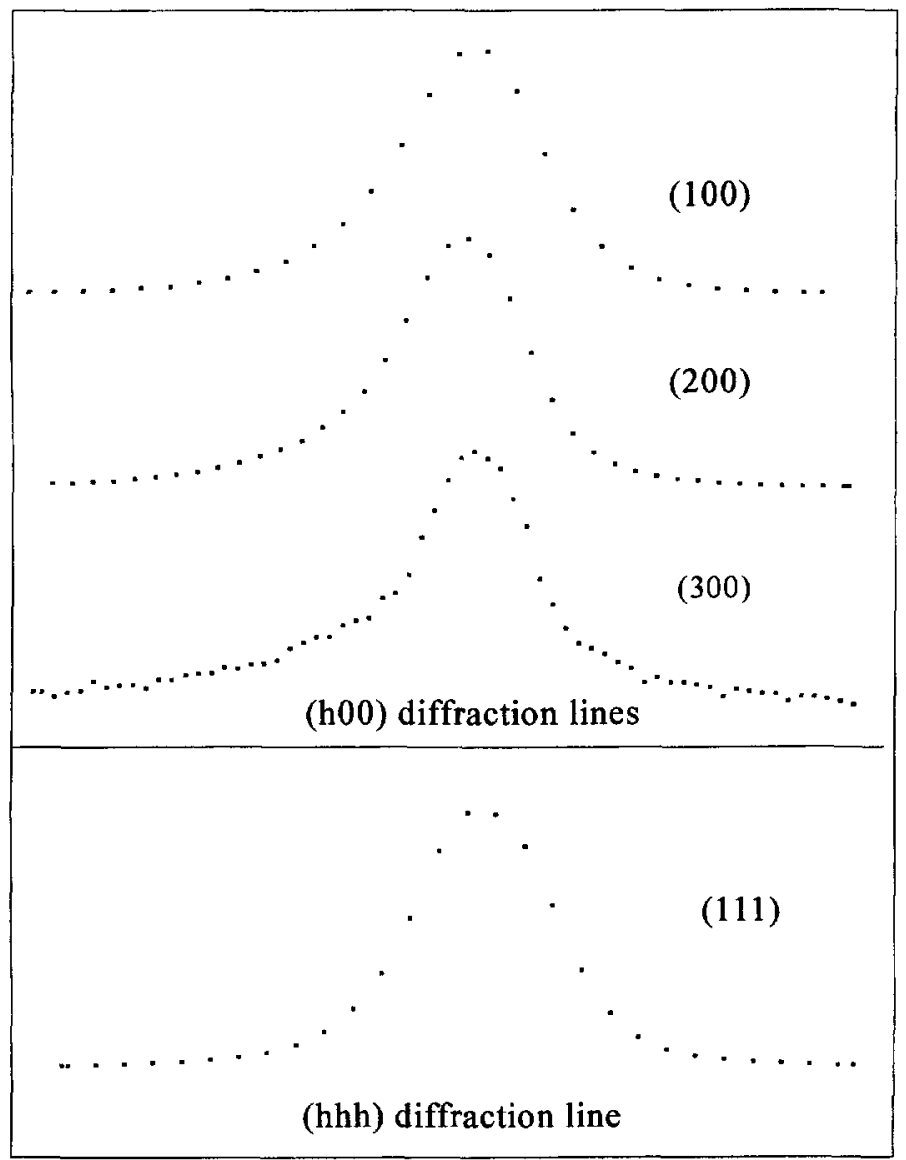

Fig. 11. - Diffraction line profiles of the perovskite phase in PMN-0.12MgO sample.

zone axis is reported Figure 12. Nanosized structural contrast is clearly observed. In the PMN-0.12MgO samples, the size of these domains varies between 2 and $15 \mathrm{~nm}$ whereas they seem to be smaller in the $0.9 \mathrm{PMN}-01 \mathrm{PT}-0.12 \mathrm{MgO}$ sample.

\subsection{Chemical Analysis By TEM}

4.2.1. Experimental Procedure and Methodology. - TEM is well adapted to analyze the complexity of this material, particularly to the nanodomains found in the perovskite grains (called hereafter "nodules"). With TEM, we dispose a tool which enables structural characterization (image and diffraction coupling) and chemical analysis by EDXS and EELS. A TEM TOPCON 002B, equipped with a Si:Li EDX detector and an Ultra Thin Window was mainly used in this investigation (Tab. I). These analytical experiments were completed by testing PMN specimens on other TEM or STEM differently equipped (Tab. I). Field Emission Gun (FEG) (TEM 3, Tab. I) associated with a cooled specimen holder (TEM 4) was used to reach the smallest beam size $(1 \mathrm{~nm})$ and to avoid any electron irradiation effect. Also, we had been able to compare Ge and Si EDXS detectors (TEM 1,2,4) and to acquire simultaneously EDXS and EELS (TEM 2,4). Each EDXS system can detect light elements down to boron. Each 


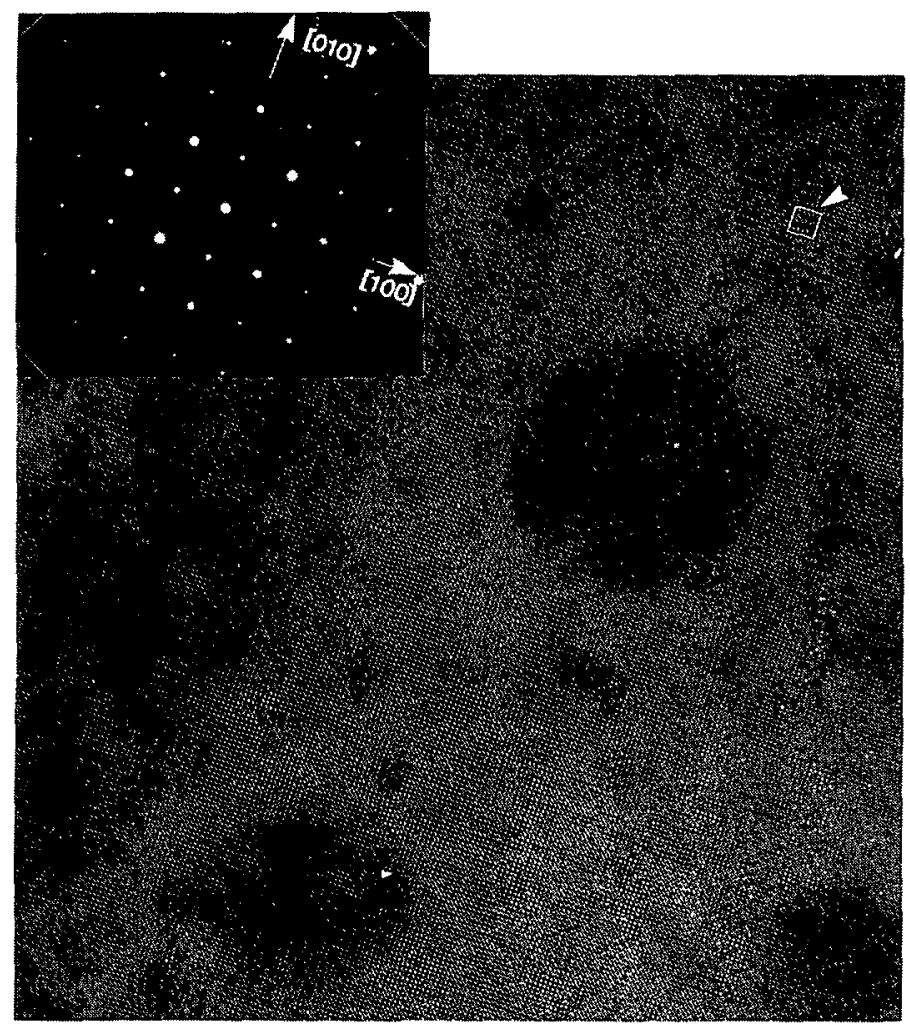

Fig. 12. - HREM image of PMN-0.12MgO sample under $\langle 001\rangle^{*}$ zone axis $(15 \mathrm{~mm}=10 \mathrm{~nm})$.

EELS detector was running in parallel mode (PEELS gathers the whole energy spectrum simultaneously). Different probe sizes were used from several $\mu \mathrm{m}$ (for global analysis) down to $5 \mathrm{~nm}$ and $1 \mathrm{~nm}$ for $\mathrm{LaB}_{6}$ and FEG sources, respectively. The reason for performing the global analysis was to confirm the local characterization by comparison with the EPMA-WDXS and SEM-EDXS results. A correct counting statistic was obtained by using acquisition times of 250-500 $\mathrm{s}$ in EDXS and $5 \mathrm{~s}$ (low loss region) to $100 \mathrm{~s}$ (inner-shell domain) in EELS (LaB source). The evolution of the spectra as a function of time (chronospectroscopy) was analyzed to control any irradiation damage under the beam for the chosen acquisition times.

The difficulties encountered in this work were due to the shape of the nodules, their nanoscale size and the low "inter-nodule" distance in areas where these domains were the smallest $(2-4 \mathrm{~nm})$. Another problem arose due to the chemical composition of this material, since it had both light and heavy elements. In EDXS, the low value of the fluorescence yield for the light elements $(\mathrm{O}, \mathrm{Mg})$, the strong absorption of the low energy photons and the increasing background signal (Bremsstrahlung) due to the heavy matrix led to poor detection efficiency. In EELS, the strong decrease of the cross section as a function of the increasing energy losses limited the energy loss domain reached at high spatial resolution. So, the $\mathrm{Pb}_{\mathrm{M} 5}$ edge $(2484 \mathrm{eV})$ was not usable due to its energy position, its shape and the partial superposition with the $\mathrm{Nb}_{\mathrm{L} 2,3}$ edge. $\mathrm{PbN}$ edge is a very weak signal and $\mathrm{Pb}_{\mathrm{O}, 5}(23.5 \mathrm{eV})$ was situated in the plasmon domain. Accordingly, simultaneous acquisition by EDXS and EELS was very useful for studying PMN (TEM (2) and (4)). The difficulty to treat correctly the characteristic signal by 
Table I - Main characterıstics of the TEM used for this work.

\begin{tabular}{|c|c|c|c|c|c|}
\hline TEM & $\begin{array}{c}\text { Accelerating } \\
\text { Voltage } \\
(\mathrm{kV})\end{array}$ & Gun & EDXS & EELS & $\begin{array}{l}\text { cold specimen } \\
\text { holder }(100 \mathrm{~K})\end{array}$ \\
\hline $\begin{array}{l}(1) \\
\text { Topcon } \\
002 \mathrm{~B}\left(^{* *}\right)\end{array}$ & 200 & $\overline{\mathrm{LaB}_{6}}$ & $\begin{array}{l}\text { Noran, } \mathrm{Si}: \mathrm{Li} \text { detector } \\
\text { Ultra Thin Window }\end{array}$ & no & no \\
\hline $\begin{array}{l}(2) \\
\text { Jeol } \\
2000 \mathrm{FX}\left({ }^{* * *}\right)\end{array}$ & 200 & $\mathrm{LaB}_{6}$ & $\begin{array}{l}\text { Oxford, Si.Li detector } \\
\text { Ultra Thin Window }\end{array}$ & Gatan 666 & yes \\
\hline $\begin{array}{l}\text { (3) } \\
\operatorname{STEM~VG}\left({ }^{* *}\right)\end{array}$ & 100 & $\begin{array}{c}\text { FEG } \\
\star\end{array}$ & no & $\begin{array}{c}\text { Gatan modified in } \\
\text { the laboratory }\end{array}$ & no \\
\hline $\begin{array}{l}(4) \\
\text { Philips } \\
\text { CM 20( }\left(^{* * *}\right)\end{array}$ & 200 & $\begin{array}{c}\text { FEG } \\
\star\end{array}$ & $\begin{array}{l}\text { Noran, Ge detector } \\
\text { Ultra Thin Window }\end{array}$ & Gatan 666 & yes \\
\hline
\end{tabular}

$\star$ FEG: Field Emission Gun

$\left({ }^{* *}\right)$ : installed in the laboratory "Physique des Solides" of the University Paris-Sud Orsay (91)

$\left({ }^{* * *}\right)$. installed in the "Centre National de la Recherche Scientifique" at Meudon (92)

$\left({ }^{* * *}\right)$ : installed in the "Centre National d'Études et de Télécommunications" at Meylan (38)

each method needed to use it together to validate the quantification and to obtain the relative atomic concentration locally.

To quantify the EDX signal, we prepared and characterized standard specimens ( $\mathrm{PbO}$, $\mathrm{Nb}_{2} \mathrm{O}_{5}, \mathrm{MgO}, \mathrm{NbSi}_{2}, \mathrm{PbTiO}_{3}$ and $\mathrm{SiO}_{2}$ ) to calculate the $k$ factors by using the Cliff-Lorimer method [23] and $\mathrm{Si}$ as the reference element. These experimental results were compared to the simulated spectra obtained from cross section and fluorescence yield calculations (using D.T.S.A. software [24], Bethe-Zaluzec [25] and Bethe-Heitler-Chapman [26] models). The relative elemental compositions were reached by normalizing the total atom concentration to $100 \%$. We were not able to assign the stoichiometry of oxygen anions at a nanometric scale in PMN. To correct the absorption effect, the Van Cappellen method [27] was applied only on the standard specimens. This method was prohibited for PMN due to its local heterogeneity and the thickness had to be estimated at each analysis point by applying a classical absorption law [28]. The first thickness estimation method is based to the difference in absorption for the same family of peaks in EDXS $\left(\mathrm{Nb}_{\mathrm{L}} / \mathrm{Nb}_{\mathrm{K}}\right.$ in the case of PMN) and the second one was based on the ratio of the elastic to the inelastic signal intensity in the EEL spectra [29]. The photon secondary emission (fluorescence effect) was neglected by taking into account the X-ray peak positions and the thinness of the TEM analysis areas [30].

The elemental quantification of the EELS spectra was achieved by calculating the partial cross sections based on a Hartree-Slater method [31] which can be successfully used for all quantifying elements included the $\mathrm{Nb}_{M}$ edge providing the integration window was located before the first sixty $\mathrm{eV}$ after the threshold.

4.2.2. Results and Discussion. - Before presenting the results in different PMN specimens, we discuss the methodology used for this quantification after testing different approaches introduced in the last paragraph. 

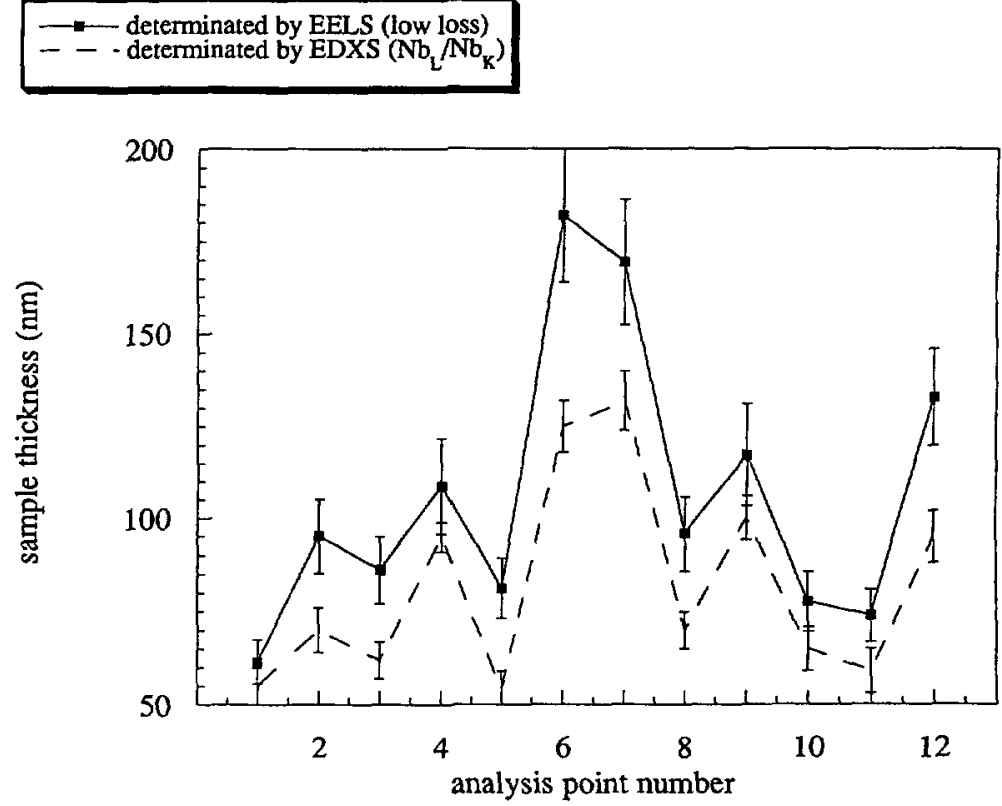

Fig 13. - Comparison of EDXS and EELS methods for estimating the sample thickness at several analysıs points. Experimental conditions were: TEM $200 \mathrm{kV}$, LaB 6 gun, cooled specimen holder, $1 \mathrm{~s}$ and $500 \mathrm{~s}$ for EELS and EDXS acquisition tımes, respectively.

The agreement between the experimental and simulated spectra was less than $15 \%$ and allowed to use the simulation to optimize the TEM settings (e.g. acquisition time, signalnoise ratio, minimum usable beam size) before performing each experiment at the nanoscale. However, the accuracy was not sufficient to obtain the $k$ factors without specimen standards mainly due to the difficulty of the fluorescence yield calculation for the $\mathrm{L}$ and $\mathrm{M}$ peaks.

Also, the validity of the EDXS quantification of PMN strongly depends on the absorption correction for the light elements which was based here on the determination of the local specimen thickness. For relative quantitative analysis, the concentration error introduced in one of the elements involved an error in the concentration of the other elements. Therefore, in PMN, for an error of $25 \mathrm{~nm}$ at a thickness of $50 \mathrm{~nm}(\Delta t / t=50 \%)$ the standard deviation were $7 \%$ and $0.3 \%$ for the $\mathrm{Mg} / \mathrm{Nb}$ and $\mathrm{Pb} / \mathrm{Nb}$ atom ratios, respectively. Taking into account the difficulty of this local investigation, Figure 13 shows the correct agreement between the thickness evolution estimated by EDXS and EELS (see Sect. 4.2.1). An over-estimation by EELS can be noticed, mainly due to the determination of the mean free path by a model which gives reasonably accurate measurements for "free electrons" [29]. However, in practice, it is better to use the EEL spectra since the acquisition time is very short, allowing to control the possible thickness evolution during the EDXS acquisition (due to contamination, irradiation damage and spatial drift). When the TEM is equipped with EDXS and EELS, the best solution to analyse PMN consists to fit in a first time, the curve obtained by EELS on the curve deduced by EDX spectra simultaneously acquired at a significant acquisition time $(>500 \mathrm{~s})$ in order to correctly extract the $\mathrm{Nb}_{\mathrm{L}} \mathrm{X}$-ray peak partially superimposed to the $\mathrm{Pb}_{\mathrm{M}}$ one (Fig. 13). In a second time, only EELS spectra are used for thickness measurements and limit the EDXS acquisition time to $250 \mathrm{~s}$. 
As the methodology allowing to quantify the chemical signals were described, the global analysis by TEM-EDXS is presenting first to corroborate the preliminary results by X-ray diffraction, EPMA-WDXS and SEM-EDXS. Using an electron beam varying between $100 \mathrm{~nm}$ and $1 \mu \mathrm{m}$ in size, the average chemical composition of the PMN grains without $\mathrm{MgO}$ inclusions was very close to the stoichiometric composition of PMN. These intra- or inter-grain $\mathrm{MgO}$ inclusions were a few hundred nanometers in size. The $\mathrm{Mg} / \mathrm{Nb}$ mean atom ratio for several grains was $0.51 \pm 0.04,0.47 \pm 0.04$ and $0.47 \pm 0.05$ for PMN, PMN-0.12MgO and 0.9PMN-0.1PT$0.12 \mathrm{MgO}$, respectively. The accuracy of these analyses included the scattering of the results and the standard deviation obtained by the multiple least square fit in extracting the characteristic signal intensity. In the case of $\mathrm{PMN}$, the pyrochlore grains $\left(\mathrm{Pb}_{2} \mathrm{Mg}_{0}{ }_{33} \mathrm{Nb}_{166} \mathrm{O}_{65}\right)$ were not included in the analyzed volume. With larger beam sizes of $1 \mu \mathrm{m}$ and $6 \mu \mathrm{m}$, the $\mathrm{MgO}$ precipitates were included in the analyzed volume and led to a relative atom concentration of $\mathrm{Mg}$ introduced during the fabrication process of PMN-0.12MgO and 0.9PMN-0.1PT-0.12MgO. The number and the size of these precipitates confirms that more than $50 \%$ of the MgO introduced in excess have not diffused in the perovskite phase. The mean atom concentration of $\mathrm{Ti}$ (1.75 at.\%) in 0.9PMN-0 1PT-0.12MgO corresponded to the introduced quantity (i.e., 10\%) of the $\mathrm{B}$ site of the perovskite phase.

The local analysis reveals for the largest nodules (\# $10 \mathrm{~nm}$ ), mainly detected in PMN$0.12 \mathrm{MgO}$, a strong increase of $\mathrm{Pb}$ and $\mathrm{O}$ and the mean chemical formula on these nodules became $\mathrm{Pb}_{1}{ }_{95} \mathrm{Mg}_{0.36} \mathrm{Nb}_{064} \mathrm{O}_{3}$ 91. Therefore, the $\mathrm{Pb} / \mathrm{Nb}$ atom ratio decreased in the matrix around these nodules (Fig. 14) and the $\mathrm{Mg} / \mathrm{Nb}$ atom ratio in the $\mathrm{B}$ site of the perovskite matrix around the nodules fluctuated between 0.38 and $0.45(\mathrm{PMN}), 0.29$ to 0.47 (PMN-0.12MgO) and 0.22 to $0.54(0.9 \mathrm{PMN}-0.1 \mathrm{PT}-0.12 \mathrm{MgO})$. The increase of $\mathrm{Nb}$ in the matrix was in good agreement with the DRX results. These results were obtained on the two TEMs (1 \& 2) and simultaneously acquired by EDXS and EELS on TEM (2) (Fig. 15). No evolution as a function of time was seen on the spectra when using the $\mathrm{LaB}_{6}$ gun down to a $5 \mathrm{~nm}$ beam. These measurements were performed on specimen regions that were not damaged by ion milling. In the case of PMN, the ion milling damage induced an amorphization of the crystal at a distance of about $10 \mathrm{~nm}$ from the sample hole and reached the relative concentration of $\mathrm{Nb}$. With the $\mathrm{LaB}_{6}$ guns and the smallest beam sizes, there was no difference between an acquisition at $100 \mathrm{~K}$ (temperature measured on the cold specimen holder) and at "room" temperature. In all cases, we note that the specimen temperature at the analysis point is higher than that measured on the sample holder but no beam damage was observed.

In the area of these widest nodules, the chemical analysis clearly reveals the local heterogeneities in $\mathrm{Pb} / \mathrm{Nb}$ and $\mathrm{Mg} / \mathrm{Nb}$ concentration in these material prepared by the method described in part 2 (Fig. 16, right part: nodule area, left part: matrix around the nodules). The composition of these nano-objects was close to a formula corresponding to an association of $\mathrm{PMN}$ and $\mathrm{PbO}$, but electron diffraction and HREM images did not reveal the presence of $\mathrm{PbO}$ precipitates. On the nodules showing a Moire effect, the Fourier Transform (FFT) confirms that this minority phase has a quadratic symmetry $(a=b=0.44 \mathrm{~nm}$ and $c=0.39 \mathrm{~nm})$. An hypothesis which will have to be confirmed is that this phase is similar to a "Popper" phase $\left(\mathrm{A}_{2} \mathrm{BO}_{4}\right)$ [32], and corresponds to successive stackings of $n$ perovskite $\left(\mathrm{ABO}_{3}\right)$ layers and $m$ cubic layers (AO).

The characterization of the smallest nodules $(2-4 \mathrm{~nm})$ was the most difficult. With the $\mathrm{LaB}_{6}$ guns, the usable size of the electron beam was greater than the nodule size. The short distance between each nodule $(3-8 \mathrm{~nm})$ generally led to the superposition of several nodules in the analyzed volume except close to the hole side of the sample foil. But in this region, we were able to exclude a modification of the composition by the "standard" ion milling. However, a second limitation arose due to the appearance of electron irradiation damage induced by very 

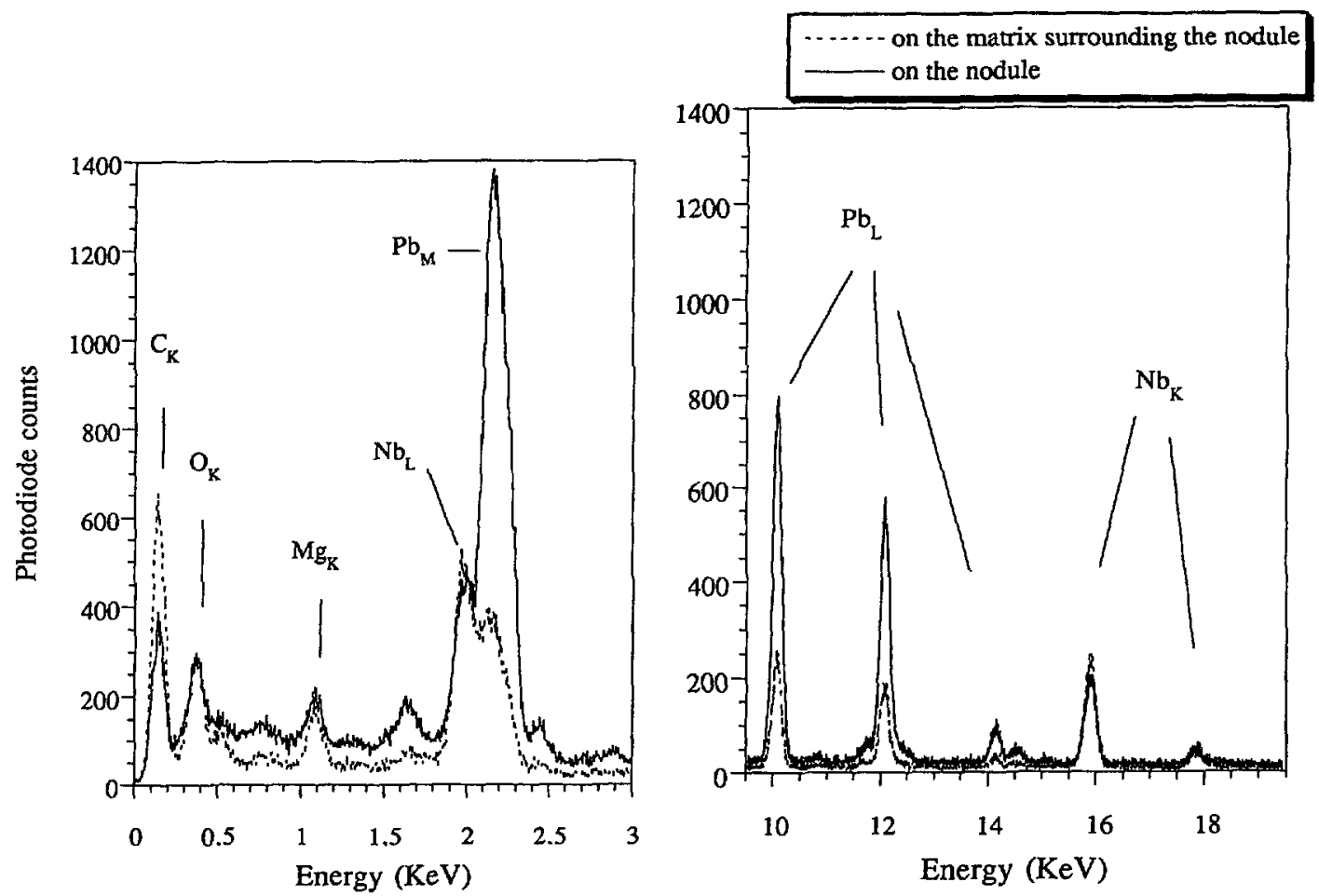

Fig. 14. - PMN-0 12MgO: comparison of EDXS spectra between a nodule of $10 \mathrm{~nm}$ in size (solid line) and in the matrix around this nodule (dotted line). TEM TOPCON (LaB 6 gun, $200 \mathrm{kV}$ ) was used.

bright, small beams in TEM equipped with a FEG source. A few tests with TEM 3 and 4 (Tab. I) operating in the chronospectroscopy mode were not sufficient to answer definitively this question. In a few cases, the signal evolved on the thinnest regions of the sample and quicker when the specimen holder was not cooled. Due to the slight spatial drift which occurs when the cooled specimen holder is used (TEM 4) and the nanoscale heterogeneity of the sample, it was difficult to unambiguously attribute this evolution to irradiation damage. Neither chemical nor structural evolution was seen on regions thicker than $50 \mathrm{~nm}$, but these areas were not compatible with the individual characterization of the smallest nodules.

Currently, in these regions, the most reliable results were obtained by using the $\mathrm{LaB}_{6}$ gun with a $5 \mathrm{~nm}$ size beam integrating several nodules. We also observed a variation of the stoichiometry for lead $\left(\mathrm{S}_{\mathrm{Pb}}\right)$ and oxygen $\left(\mathrm{S}_{\mathrm{O}}\right): 2.5<\mathrm{S}_{\mathrm{O}}<3.7$ and $0.64<\mathrm{S}_{\mathrm{Pb}}<1.4$ (nominal composition of $\mathrm{PMN}$ : $\mathrm{S}_{\mathrm{O}}=3$ and $\mathrm{S}_{\mathrm{Pb}}=1$ ). This suggested there was no difference between the small and the big nodules but it should be verified in future experiments. We will prepare TEM thin specimen by the "tripod" mechanical polishing [33] to eliminate the damaged zones up to the thinnest areas. Under these conditions, it will be possible to isolate the small nodules and analyse them. A complementary analysis to these chemical investigations would consist in studying the contrast of the HREM images not only to validate the existence of the "Popper" structure, but also to determine the origin of the substructure observed on diffraction patterns. This substructure are not presently correlated to the nodules but might be associated with smallest heterogeneities than the nodules. EELS spectra offer more information than 


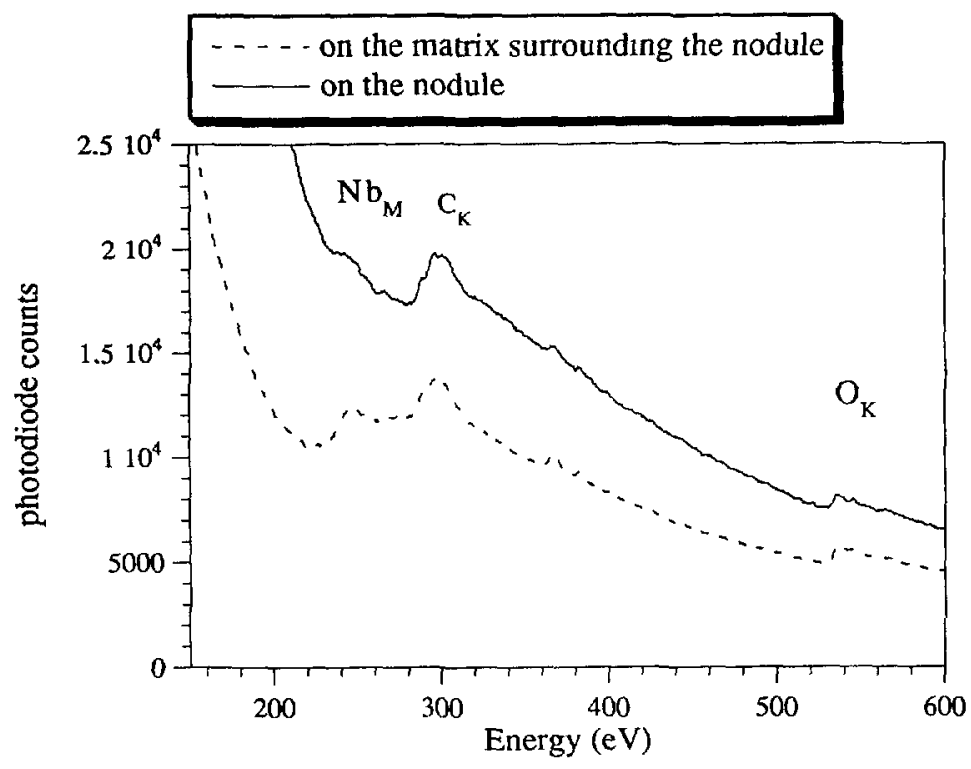

Fig. 15. - PMN-0.12MgO: comparison of EELS spectra for a nodule of $10 \mathrm{~nm}$ in size (solid line) and for the matrix around this nodule (dotted line) EELS spectra conditions were: $1 \mathrm{eV} / \mathrm{ch}$ and $10 \mathrm{mrad}$, respectively, for the energy dispersion and the collection angle

EDX spectra, which are limited to elemental composition. This is due to the better energy resolution in EELS $(0.5 \mathrm{eV}-1 \mathrm{eV})$ compared to $70 \mathrm{eV}$ and $140 \mathrm{eV}$, respectively, for $\mathrm{C}_{\mathrm{K}}$ and $\mathrm{Mn}_{\mathrm{K}}$ in EDXS. A fine structure (ELNES) is present and can be interpreted as a "fingerprint" of the electronic structure and the chemical bonding down to nanoscale. This type of information is very similar to X-ray absorption spectroscopy (XANES: X-ray Absorption Near Edge Structure, EXAFS: Extended X-ray Absorption Fine Structure) but with a nanometric spatial resolution compared to the macroscopic one obtained on a synchrotron source. This investigation is starting and will complete the present study.

Combining these local and global chemical analyses, we propose the following reaction mechanism: $\mathrm{PbO}$ diffusion is accelerated by the $\mathrm{MgO}$ excess, leading locally to its partial precipitation. $\mathrm{PbO}$ associated with a perovskite phase and $\mathrm{Mg}$ enrichment produces the nodules. Simultaneously, in the matrix surrounding the nodules, the volatilization of $\mathrm{PbO}$ is associated with $\mathrm{Mg}$ loss and $\mathrm{Nb}$ enrichment. However, in the zone of the largest nodules, the $\mathrm{Mg} / \mathrm{Nb}$ atom ratio did not reach 1 (Fig. 16). Taking into account the thickness of the analyzed volume and assuming a spherical shape of the nodule, the mean value of the $\mathrm{Mg} / \mathrm{Nb}$ ratio would be about 0.8 in the largest nodules. The initial excess of $\mathrm{MgO}$ increases the $\mathrm{Pb}$ rich nodule sizes (PMN-0.12MgO) but also allows a larger $\mathrm{PbO}$ deficiency of the matrix without pyrochlore formation, compared to stoichiometric PMN samples (Fig. 16). So, this mechanism could be at the origin of the stabilization of PMN perovskite phase by $\mathrm{MgO}$ excess. This one will be clarified in light of these new results in a next paper. Moreover, the addition of $\mathrm{TiO}_{2}$ seems to limit the diffusion of $\mathrm{PbO}$ reducing the heterogeneity of the material and consequently the nodule size (0.9PMN-0.1PT-0.12MgO). In this last material, an $\mathrm{MgO}$ nano-precipitation is observed (Fig. 17) which can be interpreted as the $\mathrm{PbO}$ diffusion slowing down. The best homogeneity of $0.9 \mathrm{PMN}-0.1 \mathrm{PT}-0.12 \mathrm{MgO}$ or in an other way, the heterogeneity at a lower scale compared to the PMN-0.12MgO, could partially explain the better dielectric characteristics. 


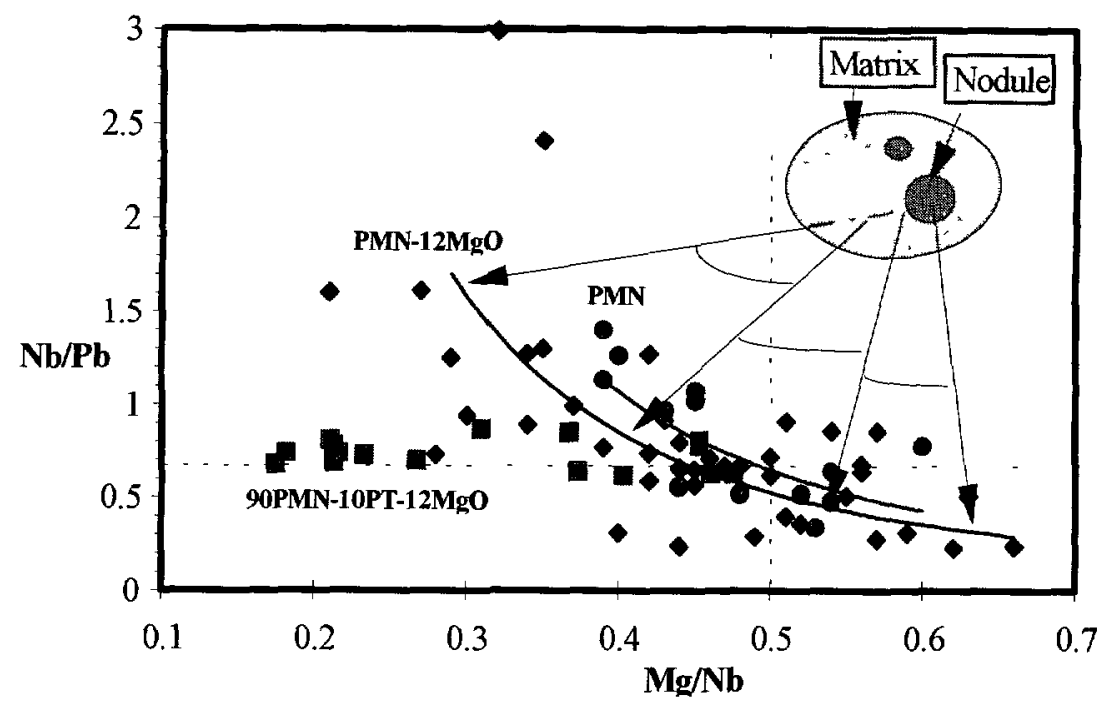

Fig. 16. - Evolution of the $\mathrm{Nb} / \mathrm{Pb}$ atom concentration ratio as a function of the $\mathrm{Mg}(+\mathrm{Ti}): \mathrm{Nb}$ atom concentration ratio in PMN $(\bullet), \mathrm{PMN}-0.12 \mathrm{MgO}(\downarrow)$ and $0.9 \mathrm{PMN}-0.1 \mathrm{PT}-0.12 \mathrm{MgO}(\boldsymbol{\square})$, determined by EDXS The dotted lines show the nominal composition ratio for the PMN perovskite.

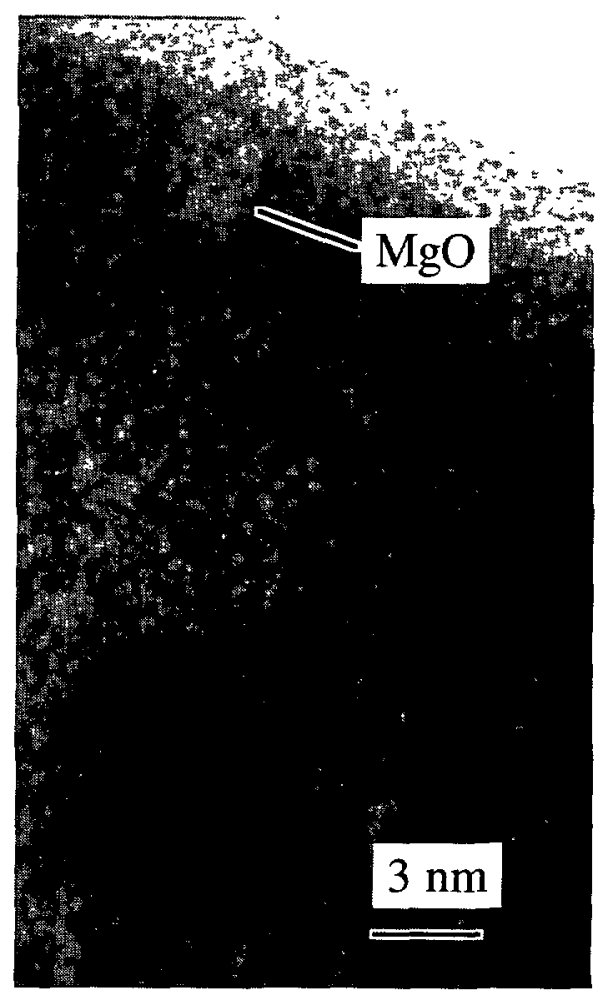

Fig. 17. - TEM image: MgO nanoprecipitate in the perovskite grain of 0.9PMN-0.1PT-0.12MgO. 
So, thanks to this study, a distribution of the chemical composition around the nominal one at a nanometric scale has been identified. This could lead to:

(i) the formation of polar clusters at a $T_{\mathrm{d}}\left(200^{\circ} \mathrm{C}\right)$ temperature, largely above the transition temperature of the nominal composition (about $40^{\circ} \mathrm{C}$ for $0.9 \mathrm{PMN}-0.1 \mathrm{PT}-0.12 \mathrm{MgO}$ ),

(ii) the nucleation and growth mechanism of polar clusters with decreasing temperature, corresponding to the successive transitions of the different local compositions.

Morover, the strong chemical heterogeneity of the materials could explain that these remain mainly paraelectric down to a very low temperature and that a high DC electric field by energy input could promote the transition up to a quasi macroscopic ferroelectric state below a certain temperature.

However, the dependence of the transition temperature as a function of the chemical composition and consequently the correlation between a polar domain and its composition at a given temperature according to its size will have to be investigated further.

\section{Conclusions}

The dielectric characterization of bulk $(1-x) \mathrm{PbMg}_{1 / 3} \mathrm{Nb}_{2 / 3} \mathrm{O}_{3}(\mathrm{PMN})-x \mathrm{PbTiO}_{3}(\mathrm{PT})$ $-0.12 \mathrm{MgO}$ with $x=0,0.05,0.10$ has revealed that a local polarization appears at a temperature largely above the temperature of maximum permittivity. This phenomenon is consistent with a nucleation mechanism of polar clusters. Moreover, a dielectric relaxation is observed for 0.9PMN-0.1PT-0.12MgO, in a large frequency range (100 Hz-15 MHz), which corresponds to a multi-Debye process with broadening of the relaxation time distribution as the temperature decreases. This suggests a nucleation and growth mechanism of polar clusters with decreasing temperature which can result from the successive transitions of different compositions. In fact, quantitative analysis on a nanometric scale performed by TEM using two spectroscopy techniques (EDXS and EELS), have revealed large fluctuations of the local composition around the nominal one: lead and magnesium deficient areas enriched in niobium coexist with nanodomains largely enriched in lead and slightly enriched in magnesium; the size of these areas depends on titanium content: the addition of titanium contributes, by stabilizing the perovskite phase, to limit the diffusion of lead oxide, which consequently increases the homogeneity of ceramics. Due to these heterogeneities, the material remains mainly paraelectric down to a very low temperature but this effect can be balanced by the application of a high electric field which induces the growth of the polar clusters by displacement of their interface with the paraelectric matrix and orientation of their polarization in the direction of the electric field so that the material can be considered mainly ferroelectric below a certain temperature. These different mechanisms relax in a frequency range which depends on the temperature and on the amplitude of the electric field.

\section{Acknowledgments}

The authors wish to thank the Francilian TEM Network and especially A. Riviere (LPSB-CNRS Meudon) for access to the JEOL 2000FX microscope at CNRS-Meudon. We also acknowledge the CNET Meylan, C. Danterroches and C. Bernardi in particular, for use of their Philips CM20-FEG TEM. Appreciation is also given to T. Epicier (GEMPPM-INSA Villeurbanne) for an useful discussion about FFT of HREM images and to B. Soulestin (ENSCI-Limoges) for the preparation of the TEM samples. And finally, we thank the DRET for their financial support of this study. 


\section{References}

[1] Smolenski G., Ferroelectrics with diffuse phase transitions, Sov. Phys. Solvd State 2 (1961) 2584.

[2] Burns G. and Dacol F.H., Ferroelectrics 104 (1990) 25.

[3] Husson E., Mathan N., Calvarin G., Gavarri J.R., Hewat A.W. and Morell A., J. Phys. Condens. Matt. 3 (1991) 8159.

[4] Husson E., Bonneau P., Calvarin G., Gavarri J.R., Hewat A.W and Morell A., X-ray and neutron diffraction studies of the diffuse phase transition in PMN ceramics, $J$. Solid State Chemistry 91 (1991) 350.

[5] Cross L.E., Relaxor ferroelectrics, Ferroelectrics 76 (1987) 241.

[6] Viehland D., Jang S.J. and Cross L.E., Freezing of the polarization fluctuations in lead magnesium niobate relaxor, J. Appl. Phys 68 (1990) 2916.

[7] Husson E., Malki M., Chabin M. and Morell A., Études diélectriques de la transition ferroélectrique induite par application d'un champ électrique dans les céramiques PMN, J. Phys. III France 4 (1994) 1151.

[8] Sommer R., Yushin N.K. and Van Der Klink J.J., Ferroelectrics 127 (1992) 235.

[9] Butcher S.J. and Daglish M., A field induced phase transition in PMN ceramics, Ferroelectrics Letters 10 (1989) 117.

[10] Hilton A.D., Randall C.A., Barber D.J. and Shrout T.R., TEM studies of PMN-PT ferroelectric relaxors, Ferroelectrics 93 (1989) 379.

[11] Lattard E., Élaboration de céramiques massives $(1-x) \mathrm{PbMg}_{033} \mathrm{Nb}_{066} \mathrm{O}_{3}-x \mathrm{PbTiO}_{3}$ avec $x=0,0,05$ et 0,1 : des caractérisations structurales au comportement électromécanique, Thèse (Université de Limoges, 1991).

[12] Lattard E., Lejeune M. et Abelard P., Propriétés électrostrictives de céramiques massives du type $\mathrm{PbMg}_{0}{ }_{33} \mathrm{Nb}_{0.66} \mathrm{O}_{3}, J$. Phys. III France 4 (1994) 1165-1187.

[13] Bouquin O., Lejeune M. and Boilot J.P., Formation of the perovskite phase in the $\mathrm{PbMg}_{033} \mathrm{Nb}_{0.66} \mathrm{O}_{3}$ system, J. Am. Ceram. Soc. 74 (1991) 1152-56.

[14] Swartz S.L. and Shrout T.R., Fabrication of perovskite lead magnesium niobate, Mat. Res. Bull. 17 (1982) 1245-1250.

[15] Masson O., Guinebretière R. and Dauger A., Reflection asymmetric powder diffraction with flat plate sample using a Curved Position Sensitive Detector (INEL CPS 120), Accepted in J. Appl. Cryst.

[16] Escure P., Lattard E., Lejeune M. and Baumard J.F., Stability of the perovskite phase in PMN-PZN-PT ceramics, J. Mat. Sct. 31 (1996) 3937-3943.

[17] Elissalde C., Ravez J. and Gaucher P., The low and high frequency dielectric relaxations in lead magnesium niobate ceramics, Mat. Scr. Eng. B 20 (1993) 318-323.

[18] Elissalde C., Ravez J. and Gaucher P., Dielectric relaxations in ceramics with compositions $(1-x) \mathrm{PbMg}_{1 / 3} \mathrm{Nb}_{2 / 3} \mathrm{O}_{3}-x \mathrm{PbTiO}_{3}(x=0,0.05,0.10$ and 0.25 , Mat. Sci. Eng. $B 22$ (1994) 303-309.

[19] Isupov V.A., Soviet Physics, Technicals Physics 1 (1956) 1846.

[20] Smolenski G.A., Physical phenomena in ferroelectrics with diffused phase transition, J. Phys. Society Jpn 28 (1970) 26-37.

[21] Carvajal L.R., FULLPROF. I.L.L. program, Grenoble France (1992).

[22] Mathan, Études structurales de céramiques diélectriques de magnésoniobate de plomb PMN en fonction de la température, Thèse (École Centrale de Paris, 1991).

[23] Goldstein, Williams D.B. and Cliff G., Quantitative X-ray Analysis in "Principles of Analytical Electrons Microscopy (D.C. Joy, D. Alton, D. Romig, Jr and J.I. Goldstein, Eds., Plenum Press, New-York, 1986) p. 155. 
[24] Desk Top Spectrum Analyser and X-ray database software (C.E. Fiori, C.R. Swyt and R.L. Myklebust, Eds., N.I.S.T., Gaithersburg MD 20899, USA, 1994).

[25] Zaluzec N.J., Quantitative X-Ray Microanalysis Instrumental considerations and application of material science, Introduction to analytical Microscopy (J.J. Hren, J.I. Goldstein and D.C. Joy, Eds., Plenum Press, New-York, 1979) p. 121.

[26] Chapman J.N., Nicholson W.A.P. and Crozier P.A., Understanding thin film X-ray spectra, J. Microscopy 136 (1984) 179-191.

[27] Van Cappellen E., The parameterless correction method in X-ray microanalysis, Micros. Microanal. Microstruct. 1 (1990) 1-22.

[28] Williams D B. and Carter C.B., Transmission Electron Microscopy, a textbook for Materials Science (Plenum Press, New-York, 1996) p. 612.

[29] Egerton R.F., Electron Energy Loss Spectroscopy in the electron microscope (Plenum Press, New-York, 1986) p. 159.

[30] Twigg M.E. and Fraser H.I., A comparison of two models for the characteristic X-ray fluorescence correction in thin foil analysis, $J$. of Microscopy 133 (1984) 61-67.

[31] Leapman R.D., Rez P. and Mayers D.F., K, L and M shell generalized oscillator strenghts and ionization cross sections for fast electron collisions, J. Chem. Phys. 72 (1980) $1232-$ 1243.

[32] Popper P. and Ruddlesden S.N., New compounds of the $\mathrm{K}_{2} \mathrm{NiF}_{4}$ type, Acta Cryst. 10 (1957) 538.

[33] Ayache J. and Albarède P.H., Application of the ionless tripod polisher to the preparation of YBCO superconducting multilayer and bulk ceramics thin films, Ultramicroscopy 60 (1995) 195-206. 